\title{
Overnight Momentum, Informational Shocks, and Late-Informed Trading in China
}

\author{
Ya Gao ${ }^{1}$, Xing $\mathrm{Han}^{2}$, Youwei $\mathrm{Li}^{3}$, Xiong Xiong ${ }^{4,5^{*}}$
}

1. Faculty of Management and Economics, Dalian University of Technology, Dalian, 116024, China

2. Department of Accountancy and Finance, University of Otago, Dunedin, 9016, New Zealand

3. Hull University Business School, University of Hull, HU6 7RX, United Kingdom

4. College of Management and Economics, Tianjin University, Tianjin 300072, China

5. China Center for Social Computing and Analytics, Tianjin, 300072, China

First version: 30-December 2017

This version: 16-September-2019

\begin{abstract}
Based on high-frequency firm-level data, this paper uncovers new empirical patterns on intraday momentum in China. First, there exists a strong intraday momentum effect at the firm level. Second, the intraday predictability stems mainly from the overnight component rather than the opening half-hour component, which is consistent with the microstructure features of the Chinese market. Third, the intraday predictability attenuates (strengthens) following large positive (negative) informational shocks, implying a striking asymmetric reaction by market participants. Finally, we document that late-informed traders are relatively less experienced or skilful. Overall, the empirical results lend support to the model of late-informed trading.
\end{abstract}

JEL classification: G12, G14, G15, G17

Keywords: intraday momentum, overnight return, price jump, late-informed trading

\footnotetext{
* Corresponding author: College of Management and Economics, Tianjin University, No. 92 Weijin Road, Nankai District, Tianjin 300072, China. Tel: +86-022-27891308, Fax: +86-022-27891308, Email: xxpeter@ jju.edu.cn (X. Xiong). Email addresses: gaoya@dlut.edu.cn (Y. Gao); xing.han@otago.ac.nz (X. Han); youwei.li@hull.ac.uk (Y.Li); xxpeter@tju.edu.cn (X.Xiong).

The authors acknowledge Brian Lucey, Yingying Wu (the discussant), and seminar participants at INFINITI (Sydney). Financial support from the National Natural Science Foundation of China (71532009, 71790594, 71571197), and the Tianjin Development Program for Innovation and Entrepreneurship, is greatly acknowledged. All remaining errors are the authors'.
} 


\title{
Overnight Momentum, Informational Shocks, and Late-Informed Trading in China
}

\begin{abstract}
Based on high-frequency firm-level data, this paper uncovers new empirical patterns on intraday momentum in China. First, there exists a strong intraday momentum effect at the firm level. Second, the intraday predictability stems mainly from the overnight component rather than the opening half-hour component, which is consistent with the microstructure features of the Chinese market. Third, the intraday predictability attenuates (strengthens) following large positive (negative) informational shocks, implying a striking asymmetric reaction by market participants. Finally, we document that late-informed traders are relatively less experienced or skilful. Overall, the empirical results lend support to the model of the late-informed trading.
\end{abstract}

JEL classification: G12, G14, G15, G17

Keywords: intraday momentum, overnight return, price jump, late-informed trading 


\section{Introduction}

Since the seminal work in Jegadeesh and Titman (1993), the tendency that stocks perform relatively well in the past continue to outperform in the intermediate horizon, the so called (cross-sectional) momentum, has drawn substantial interests from academia and practitioners alike (Carhart 1997; Cooper et al. 2004; Nijman et al. 2004; Sagi \& Seasholes 2007; Min \& $\underline{\text { Kim 2016)}})^{2}$ Besides this well-established cross-sectional momentum, Moskowitz et al. (2012) document a strong time-series momentum pattern that the past 12-month return predicts the subsequent one-month return, which prevails in a number of asset classes (Moskowitz et al. 2012; Georgopoulou \& Wang 2016).

More recently, Gao et al. (2018) extend the momentum literature to the field of intraday highfrequency and uncover a striking intraday time-series predictability in the US S\&P 500 exchange-traded fund market. That is, the first half-hour return positively predicts the last halfhour return within the same trading day. ${ }^{3}$ They argue that the intraday momentum is consistent with both the (Bogousslavsky 2016) model of infrequent portfolio rebalancing and the model of late-informed trading near the market close.

To shed new light on the intraday momentum effect, this paper extends the empirical analysis to the firm level by examining a comprehensive high-frequency dataset in the Chinese A-share market. Our focus on the Chinese stock market is mainly motivated by its special trading regulation and market designs. To be specific, China has adopted a " $T+1$ trading rule" since 1995, which prevents investors from selling stocks bought on the same day (Guo et al. 2012). This unique trading rule, however, goes counter to the settings of the infrequent portfolio rebalancing model, as traders who hold an excess position in the asset could not rebalance at the intraday frequency. ${ }^{4}$ In other words, the $T+1$ trading rule offers an ideal setting to verify the rich empirical predictions of the Gao et al. (2018) model of late-informed trading.

\footnotetext{
2 The strong cross-sectional momentum pattern prevails in the international equity markets. For example, Rouwenhorst (1998) examined 18 European stock markets, Fama and French (2012) covered 23 developed markets in North America, Europe, and Asia-Pacific, Asness et al. (2013) provided confirmatory evidence in the US, UK, Japan, and the EU market, and Barroso and Santa-Clara (2015) covered 21 stock markets. Cross-sectional momentum also exists in different asset classes. See Moskowitz et al. (2012), Menkhoff et al. (2012) and Asness et al. (2013) for evidences in the equities, currencies, government bonds, and commodity futures markets.

${ }^{3}$ Elaut et al. (2018) and Zhang et al. (2019) document similar intraday momentum effect in the FX and emerging markets, respectively.

${ }^{4}$ The Bogousslavsky (2016) model of infrequent portfolio rebalancing assumes that a subset of infrequent traders rebalances at the designated frequency to generate the observed positive return predictability While it is a powerful theoretical model which could explain the return predictability at daily, weekly, and other frequencies, it is less plausible to explain the intraday pattern in China. This is because China adopts a unique " $T+1$ trading rule" which technically forbids investors from rebalancing at the intraday frequency.
} 
Along the line of the high-frequency return predictability (Heston et al. 2010; Elaut et al. 2018; Gao et al. 2018), our contribution to the emerging high-frequency momentum literature is at least threefold.

First, in contrast to the prior work that focuses on the market level (Gao et al. 2018; Zhang et al. 2019), we analyse whether the intraday time-series predictability exists for individual stocks. Similar to findings at the aggregated level, we document a strong intraday time-series momentum pattern at the firm level: stock return of the first half-hour is a strong positive predictor for the last half-hour return at the market closure. Moreover, this firm-level return predictability is robust across subsamples that differ in market capitalization (and other firm characteristics), implying an intraday time-series trading strategy is implementable for individual stocks as well.

Second, we uncover the (empirical) source of the intraday return predictability by decomposing the Gao et al. (2018) first half-hour return into two non-overlapping return components: the overnight component and the opening half-hour component. Motivated by the microstructure design of the Chinese stock market, in which a pre-open call auction is integrated with the continuous trading session(s), we explore its implications for intraday momentum. In principle, the pre-open call auction should facilitate price discovery as it provides more rooms for trading beyond normal trading sessions (Madhavan 1992). This is crucial for a market with heterogeneous investors, as those early-informed traders could act on the "overnight" informational flows in pre-open call auction before the continuous trading session starts.

To the extent that overnight return (determined by the pre-open call market) carries significant price-related information, we would expect that the overnight return component positively predicts the price movement in the last half-hour before market closure. This is also consistent with the prediction of the model of late-informed trading as late-informed traders base their intraday trading signal on the observed overnight return that are informative. Empirically, we find consistent evidence: Both the panel regression and firm-by-firm regressions yield the same conclusion that the intraday momentum stems mainly from the overnight return component. In comparison, the opening half-hour return provides little, if any, predictability for the last halfhour return during the trading day. From a practical perspective, the stronger predictive power of overnight return is also beneficial to all market participants, as they have more time to execute the intraday trading strategy throughout the day. 
Third, we explore the interaction between firm-level informational shocks and the intraday momentum. As another key finding of this paper, we document a striking asymmetric pattern of intraday (overnight) momentum subsequent to large informational shocks. Using identified price jumps as the proxy for large informational shocks (see Ball and Torous (1985), Johannes (2004), Maheu and McCurdy (2004), and Cremers et al. (2015) for theoretical justification), we find the return predictability of first half-hour return or overnight return is much stronger following negative jump days than positive jump days. This striking asymmetric post-jump momentum pattern is similar to the prior (cross-sectional) momentum literature that investors react differently to good news and bad news (Hong et al. 2000), and can be reconciled with a number of real world mechanisms (or frictions) such as biased managerial disclosure of good news versus bad news of a firm and the existence of stringent short-sales impediments. Therefore, bad news travels slowly as it takes longer time for the market to digest the informational content of pessimist news. (Pritamani \& Singal 2001; $\underline{\text { Park \& Lee 2014; Brennan }}$ et al. 2015).

Finally, based on a proprietary brokerage account dataset, we make the first attempt to verify the model predictions of the late-informed trading. Given that investors are heterogeneous in their ability to collect and interpret information, the key empirical prediction of the lateinformed trading is that those who trade at later time of the day (i.e., late-informed traders) are relatively less experienced or skilful compared to those who trade mainly in the pre-open call auction and/or the early trading session. Empirically, we find confirmatory evidence that there exists a substantial fraction of late-informed traders (i.e., approximately $15 \%$ of all active traders) who concentrated their trading activity in the latter-half of the trading day, and in particular, the last half-hour of the continuous trading session. In comparison, early-informed traders, defined as those traded during the pre-open call auction, comprises around $6.5 \%$ of all active traders. In general, we find early-informed traders have more trading experience (measured in years) and are better educated (i.e., bachelor degree or higher) than their lateinformed peers (See Table 8 and Table A4 in the appendix). Therefore, for late-informed traders who have less ability to process the overnight information (or hesitate to trade until they confirm the precision of the overnight information), the trading session near market close (i.e., the last half-hour) stands for an important timing for them to utilize their (late-learned) information to trade.

In robustness tests and further analysis, we find similar evidence as in prior literature that intraday momentum pattern is much stronger in financial crisis than in normal periods 
(Avramov \& Hore 2017; Elaut et al. 2018; Gao et al. 2018). The magnitude of the slope coefficient on the first half-hour return or overnight return almost tripled during market crashes, indicating stronger return comovements in bad times.

The remainder of this paper is organized as follows: Section 2 documents the data sources and the trading mechanisms in China. Section 3 provides the baseline results of intraday momentum in the Chinese stock market for the full sample and the subsamples. Section 4 provides an empirical decomposition to validate the sources of the intraday momentum. Section 5 further tests the post-jump-day effect of intraday momentum. Section 6 validates the model predictions of the late-informed trading. Section 7 performs a battery of robustness tests and further analyses. Section 8 concludes the paper.

\section{Data and Trade Mechanisms}

\subsection{Data Sources}

We compile a high-frequency dataset of the Chinese A-shares over the sample period from January 1996 to May 2018. Our data source is from the Thomson Reuters Tick History (TRTH) database via the Securities Industry Research Centre of Asia-Pacific (SIRCA). For comprehensiveness, we retrieve all Chinese A-shares available in the TRTH database, which includes 3,596 stocks. We apply a uniform data filtering rule. That is, we require a stock to have at least a full year's data (corresponding to 244 trading days, the average annual trading days over the entire sample period) to be included in our final sample. After applying this filter rule, our final sample contains 3,224 valid stocks in total. This includes 1,271 stocks listed in the Shanghai Stock Exchange (SHSE), which spans from January 1996 to May 2018; 467 stocks in the main board of the Shenzhen Stock Exchange (SZSE), which spans from November 2001 to May 2018; 852 stocks in the SME board of SZSE, which spans from June 2004 to May 2018; 634 stocks in the ChiNext board of SZSE, which spans from November 2009 to May 2018.

Note China has very rigid rules for stocks to be listed on the different boards of the security exchanges, which is mainly based on firm size. According to the listing rule, all A-shares in the Shanghai Stock Exchange are on the Main board. The same applies to all stocks on the Main board of SZSE. In general, stocks on the Main board need to have at least 30 million shares and more than 50 million Chinese yuan (CNY) share capital before IPO, and more than $25 \%$ tradable shares after being listed; stocks on the SME board need to have at least 30 million 
shares before the IPO, more than 50 million CNY share capital after being listed; stocks on the ChiNext board need to have more than 30 million CNY share capital after being listed.

Following Gao et al. (2018), we calculate the intraday return at each half-hour interval for our empirical analysis in the following section. The full description of the variable construction is available in Appendix A.1.

\subsection{Trade Mechanism}

Since its inception in 1990, the Chinese A-share market functions as a pure order-driven market. SHSE and SZSE adopt a fully automated and screen-based trading platform (i.e., an electronic open Limit Order Book (LOB)) to consolidate all the trades and quotes during the trading hours, with no designated market makers (specialists).

Besides the continuously trading system (i.e., LOB), the trading mechanism in the Chinese Ashare market is integrated with a 10-minute pre-open call auction held between 9:15 and 9:25 (Gerace et al. 2015)..$^{5}$ The pre-open call auction is designed to help uncover the opening price, which is the clearing price that maximizes the trading volume based on all the collected limit orders during the pre-open session. Orders that are not executed in the pre-open call auction are automatically transferred to the period of continuous trading.

Following the pre-open call auction, there are two normal trading sessions, during which continuous trading is conducted through the submission of limit or market orders. During the continuous trading sessions, (unexecuted) limit orders can be modified or cancelled. The morning trading session starts at 9:30 for two consecutive hours, and then stops at 11:30 for a 90-minute lunch break. The afternoon trading session resumes at 13:00. There is no special trading mechanism to close the morning session or open the afternoon session. In SHSE, the afternoon session lasts for another two consecutive hours and closes at 15:00 for that day. Accordingly, the closing price in SHSE is generated by taking a volume-weighted average of the trading prices of the final minute of the afternoon session. In SZSE, however, the afternoon session stops at 14:57, which is followed by a 3-minute closing call auction between 14:57 and 15:00 to determine the closing price of the day. ${ }^{6}$

\footnotetext{
${ }^{5}$ During the 10-minute pre-open call auction, investors could place limit orders. However, no orders can be modified or withdrawn between 9:20 and 9:25.

${ }^{6}$ The transition from continuous trading to the closing call auction is almost "unnoticeable", as all remaining limit orders at 14:57 are routed automatically to the closing auction. In addition, investors could submit new limit orders
} 


\section{Intraday Momentum at the Firm Level}

\subsection{Baseline Results}

In this section, we test whether the intraday momentum pattern exists at the firm level. That is, whether the first half-hour return (denoted as $r_{1 s t, t}$ ) is able to predict the last half-hour return of the trading day $t$ for an individual stock.

Following Gao et al. (2018), we consider the following predictive regression model:

$$
r_{\text {last }, t}=\alpha+\beta_{1 s t} \times r_{1 s t, t}+\beta_{14: 30} \times r_{14: 30, t}+F E+\varepsilon_{t},
$$

where $r_{1 s t, t}$ is the first half-hour return calculated using the close price of the prior trading day and the stock price at 10:00 of the current trading day, $r_{14: 30, t}$ is the penultimate half-hour return calculated using the stock prices at 14:00 and 14:30 of the current trading day. The dependent variable $r_{\text {last }, t}$ is the last half-hour return, which is calculated from the stock prices at 14:30 and 15:00 (i.e., market close) of the current trading day. $F E$ denote the terms for the firm-fixed effects and time-fixed effects. The inclusion of the penultimate half-hour return is to control the very short-term return predictability (i.e., autocorrelation) at the intraday level. Therefore, the slope coefficients, $\beta_{1 s t}$ and $\beta_{14: 30}$, measure the predictability of the first halfhour return and the penultimate half-hour return on the last half-hour return, respectively.

\section{[ insert table 1 here ]}

Table 1 presents the estimation results of the panel regression with fixed effects. The first model specification (column 1) represents the univariate case with the first half-hour return as the predictive variable. As it stands, the slope coefficient on the first half-hour return amounts to 1.92 and is statistically significant at the $1 \%$ level. ${ }^{7}$ The second model specification (column 2) represents the univariate case with the penultimate half-hour return as the predictive variable. Its slope coefficient amounts to 6.16 and is also highly statistically significant at the $1 \%$ level. The third model specification (column 3) represents the bivariate case with both the first halfhour return and the penultimate half-hour return as the predictive variables. It should be noted

during the 3-minute closing auction. After submission, these orders can no longer be modified or withdrawn during the closing auction period.

${ }^{7}$ To be conservative, we do not annualize the slope coefficients in our predictive regressions. Therefore, our slope coefficients are in general smaller than those in Gao et al. (2018). In fact, a one percent change of the first halfhour return would indicate an annualized 4.68 percent change of the last half-hour return, which is significant from a pure economics perspective. 
after accounting for the very short-term return predictability (i.e., penultimate half-hour return), the predictive power of the first half-hour return on the last half-hour return remains strong with a coefficient of 1.83 , which is significant at the $1 \%$ level.

In terms of the model fit, the adjusted $R$-squares are $0.16 \%, 0.37 \%$, and $0.51 \%$ for the three model specifications, respectively. ${ }^{8}$ This is consistent with the prior findings in Zhang et al. (2019) that the penultimate half-hour return has stronger return predictability than the first halfhour return in China, which is contrary to the pattern in the US (Gao et al. 2018). In fact, both return predictors remain strong in predicting the last half-hour return, as the adjusted $R$-square increased from $0.37 \%$ to $0.51 \%$ in the bivariate case. This, coupled with the significant coefficient of the first half-hour return, implies that the information content of the first halfhour return is not subsumed by the penultimate half-hour return. ${ }^{9}$

To sum up, intraday momentum effect remains strong at the firm level in the Chinese stock market: The first half-hour return strongly predicts the last half-hour return for individual stocks.

\subsection{Subsample Analysis}

Results in the prior subsection confirms the strong intraday time-series momentum effect at the firm level in the Chinese A-share market. In this part, we re-test the intraday time-series pattern with subsamples. This is motivated by the empirical findings in Hong et al. (2000) that the profitability of momentum strategies declines sharply with firm size, as the smallest stocks are influenced the most by return momentum. Our aim is to verify whether the same pattern holds at the intraday frequency.

Following the listing rules in the Chinese A-share market, we assign stocks to three different groups based on their board of listing: The Main board refers to all stocks listed in the Shanghai Stock Exchange and those in the main board of the Shenzhen Stock Exchange. The SME board

\footnotetext{
${ }^{8}$ The model fit is reasonable considering that the predictive regressions usually have relatively low $R^{2}$ at the high frequency. For example, Yamamoto (2012) adopts the intraday technical analysis of individual stocks on the Tokyo Stock Exchange and finds the joint regression explanatory power of lagged midpoint return, order flow, and order imbalance ranges from $0.21 \%$ to $0.50 \%$ for different size groups. Renault (2017) uses intraday online sentiment data to predict the half hour return in the U.S. stock market and find the regression explanatory power for the first half-hour return, twelfth half-hour return, and the last half-hour return varies from $-0.14 \%$ to $1.35 \%$.

${ }^{9}$ In unreported analysis, we also control for the first half-hour return after the lunch break. The intraday momentum effect remains robust. For parsimonious purpose, we retain in our baseline model only the first halfhour and the penultimate half-hour returns. We thank an anonymous referee for suggesting this additional robustness check.
} 
consists of all A-shares that fulfill the criteria of small and medium enterprises. The ChiNext board consists of all A-shares identified as small/tiny enterprises engaged in independent innovations and/or other growing venture enterprises. The existence of the three alternative boards reflects China's multi-tier capital market system and offers a simple yet rigid classification of the firm size (see footnote 9). Admittedly, an alternative size-based classification would be to divide all listed firms into size-tercile groups based on the market value of equity as in Han and $\mathrm{Li}$ (2017). In fact, our findings remain unchanged under the alternative size classification method.

Table A1. in the appendix provides the market statistics of the three boards of the Chinese Ashare market. A number of salient features emerge from the table. First, from the time dimension there exhibits strong growth for all the three boards, as reflected in the number of listed firms, total market capitalization, total number of shares outstanding, and total trading volume. Second, there exhibits a size pattern, as stocks in the Main board have the largest (total) market capitalization, number of shares outstanding, and trading volume, which is followed by the SME board and the ChiNext board. This provides support for us to sort stocks into size groups based on their board of listing. Third, there exhibits two dramatic market downturns (i.e., financial crises) as in the year of 2008 and 2016 during our sample period, which we examine in more detail in Section 7.

To uncover the intraday momentum pattern in the cross section, we re-test the predictive regression with the subsamples.

\section{[ insert table 2 here ]}

Table 2 presents the estimation results of the panel regression of the three subsamples with fixed effects (i.e., equation [3.1]). Looking across the three groups, there exhibits a size pattern, as the slope coefficient on the first half-hour return increases monotonically from the Main board to the SME board and to the ChiNext board, whether we control for the effect of the penultimate half-hour return or not. In addition, the explanatory power also increases monotonically from the Main board to the SME board and to the ChiNext board $(0.12 \%, 0.24 \%$ and $0.31 \%$ in the univariate case). When examining the autocorrelation effect due to the penultimate half-hour return, we find a similar monotonically increasing pattern for the slope coefficient and the explanatory power.

Overall, we confirm that intraday time-series momentum exists in all three subgroups, and the penultimate half-hour return remains a strong return predictor as compared to the first half- 
hour return. Moreover, we more or less confirm the size effect of the intraday time-series momentum in the cross section, as the return predictability in the SME and ChiNext boards are stronger than that in the Main board. In other words, stocks with smaller market capitalization exhibit larger intraday momentum pattern over time, which is consistent with prior literature such as Rouwenhorst (1998), Hong et al. (2000), Chui et al. (2010), and Novy-Marx (2012), among others that studying momentum at the low frequency (i.e., monthly).

\section{Decomposition of the First Half-Hour Return}

\subsection{Overnight Momentum versus Opening Half-hour Momentum}

In this section, we decompose the Gao et al. (2018) first half-hour return into two nonoverlapping components: the overnight return component and the opening half-hour return component. The former is defined as the price movement from the closing price of the prior trading day to the opening price as of 9:30, while the latter measures the intraday price movement between 9:30 and 10:00 of the current day. The partition into the two nonoverlapping components is mainly motivated for two reasons.

First, from a pure market microstructure perspective, the two return components stem from vastly different trading mechanisms. As is explained in Subsection 2.2, the overnight component (or opening price) is determined by the 10-minute pre-open call auction, which offers the earliest trading opportunities (beyond the normal trading hours) to explore the informational flows during the overnight period (i.e., in between the market closure of the prior trading day and the opening of the continuous trading in the current trading day). In principle, call markets can aggregate information by pooling orders and thus facilitate price discovery even when continuous markets may fail due to high information asymmetry (Madhavan 1992). The (Walrasian-type) call auction matches supply and demand (i.e., limit buy and sell orders) directly by setting a uniform clearing price (i.e., the opening price) to maximize the transaction volume. Thus, it is claimed to facilitate price discovery by lowering execution and market impact costs, eliminating the risk of front-running and informational disclosure, and lowering price manipulation (Economides \& Schwartz 1995). In comparison, the opening half-hour return is determined in the continuous trading sessions (i.e., the LOB), in which (early-)informed traders tend to "disguise" their trading motive. Moreover, trading in the continuous session could also be related to other motives such as liquidity provision (i.e., earning the bid-ask spread). In other words, the opening half-hour component could be more 
of a mixed price signal. Therefore, it is natural to assume that the two non-overlapping components offer different price-related information, which might lead to the documented intraday periodicity.

Second, from the perspective of the model of late-informed trading, it helps to identify which trading signal do the late-informed traders act upon. Within the model of late-informed trading, investors are heterogeneous in their ability to collect and interpret information. Those who have better skills to process the overnight information (i.e., early-informed traders) can act early in the morning trading session and even the pre-open call auction. However, for those who have less ability to process the overnight information or those who hesitate to trade until they confirm the precision of the overnight information, the last half-hour trading period stands for another important timing for them to utilize their (late-learned) information to trade, and thus exploiting the informational content. Therefore, it helps to identify which return component is the (major) trading signal utilized by the late-informed traders.

To test (separately) the predictive power of the overnight component and the opening half-hour component, we adopt the following predictive regression model.

$$
r_{\text {last }, t}=\alpha+\beta_{o v} \times r_{o v, t}+\beta_{10: 00} \times r_{10: 00, t}+\beta_{14: 30} \times r_{14: 30, t}+F E+\varepsilon_{t}
$$

where $r_{o v, t}$ denotes the overnight component calculates from the closing price of the prior trading day to the opening price of the current day, while $r_{10: 00, t}$ the opening half-hour component calculated from the stock prices at 9:30 and 10:00 of the current day. The penultimate half-hour return, $r_{14: 30, t}$, is calculated from the stock prices at 14:00 and 14:30 of the current trading day. The dependent variable, $r_{\text {last }, t}$, is the last half-hour return within the day, calculated from the stock prices at 14:30 and 15:00. FE denotes the terms of fixed effects. Again, we require a firm to have at least one full year's available data (i.e., 244 trading days, the average annual trading days in China) to be included in the panel regression. The slope coefficients $\beta_{o v}$ and $\beta_{10: 00}$ measure the predictability of the two non-overlapping return components on the last half-hour return, respectively.

\section{[ insert table 3 here ]}

Table 3 presents the estimation results of the panel regression with fixed effects. The first model specification (column 1) represents the univariate predictive regression with the overnight return as the sole predictive variable. Compared to the univariate case of the first half-hour return in column 1 of table 1, the impact of the overnight return component is much 
stronger, both in the magnitude of the slope coefficient (from 1.92 to 2.88) and in terms of the explanatory power (from $0.16 \%$ to $0.22 \%$ ). After controlling the overnight component, the opening half-hour component exhibits some positive predictability on the last half-hour return (column 2). However, its influence is much weaker as its slope coefficient is approximately one-fifth of that of the overnight component. Moreover, adding the opening half-hour component only slightly increases the explanatory power from $0.22 \%$ to $0.23 \%$. Column 3 takes into account the impact of the penultimate half-hour return when testing the predictive power of the overnight return component. The impact of the overnight component remains virtually intact with a slope coefficient of 2.78 that is statistically significant at the $1 \%$ level. Moreover, there exhibits strong short-term return predictability induced by the penultimate half-hour return, as its slope coefficient is 6.02, much larger in magnitude than the overnight component. The model fit also jumps dramatically from $0.22 \%$ to $0.57 \%$. Finally, the last column considers simultaneously the overnight component, the opening half-hour component, and the penultimate half-hour return. The results are highly similar, as we document a strong short-term predictability (due to the penultimate half-hour return) and intraday momentum due to the overnight component.

\subsection{Alternative Versions of the Opening Half-hour Return}

To shed more light on the empirical source(s) of intraday momentum, we also test alternative versions of the opening half-hour return. That is, we define alternative versions of opening half-hour return using the price movements during the first 5, 10, 15, 20, 25, and 30 minutes in the continuous trading session, respectively. Gao et al. (2018) also test similar alternative definitions of first half-hour return for intraday momentum, but they do not separate the overnight component from these alternative measures.

Again, our aim is to test the predictive power of the overnight component and the alternative opening half-hour component, while controlling the short-term autocorrelation (i.e., the penultimate half-hour return).

\section{[ insert table 4 here ]}

Table 4 presents the estimation results of the panel regression with fixed effects. Interestingly, as we retain the same model specification but use alternative versions of the opening half-hour component, the slope coefficient on the (alternative) opening half-hour component flips sign from negative to positive. The changing sign of the slope coefficients is consistent with the fact 
that trading in the continuous session is related to different motives such as information digestion and/or liquidity provision, which results in a mixed price signal for the last half-hour return.

In comparison, the slope coefficients on the overnight component and the penultimate halfhour return retain the same positive sign and magnitude, implying non-overlapping pricerelated information for the last half-hour return.

Overall, when we interpret the results from Tables $\mathbf{3}$ and $\mathbf{4}$ collectively, it is clear that the overnight return (determined from the pre-open call auction) is the main source of the intraday momentum effect. In fact, after controlling the penultimate half-hour return, the overnight return has a larger slope coefficient than that of the first-half hour return (in Table 1). This is consistent with the projection from the microstructure perspective that trading in the pre-open call market is more likely to be informational driven, which results in a more reliable price signal with stronger predictive power. From the perspective of the model of late-informed trading, it also implies that the overnight component is (possibly) the more reliable trading signal that the late-informed traders could act upon, given that the predictive sign of the opening half-hour returns varies under alternative measures. Finally, it should be noted that from the practical perspective, the stronger the "overnight momentum", the more trading opportunities left for traders as they would have more time to execute trades during the continuous trading sessions. Therefore, in the remaining part of this paper, we present the results for both the first half-hour return and the overnight return.

\section{Intraday Momentum and Informational Shocks}

To shed more light on the (possible) link between intraday momentum and late-informed trading, we verify whether there exists a dynamic intraday time-series predictability. For example, Hong et al. (2000) find negative firm-specific information diffuses gradually across the investing public, leading to a stronger momentum pattern for loser stocks. To the extent that intraday high-frequency momentum reflects the tendency that late-informed traders commence trading based on the observed price signal, the informational role of the first halfhour return (or the overnight return) might differ between good and bad information being disclosed to the market. Our logic is as follows. As long as managers prefer higher to lower stock prices, they will have the strong tendency to disclose positive news about the firm more efficiently (and possibly in a more unambiguous manner). Therefore, following the disclosure 
of positive news, the informational role of first half-hour return (or overnight return) will become weaker (i.e., a smaller post-event intraday momentum effect) as there is less informational uncertainty about the firm. On the contrary, managers would not have the same motivation to disclose the negative news about the firms to the public. Even if the managerial disclosure of negative news is in the same unbiased manner as for positive news, it might still take longer time for the investing public to digest the informational content of the negative news due to the impediment of short-sales constraints (Hong et al. 2000). Based on these arguments, the intraday momentum effect might be stronger following negative news about the firm. To sum up, our main testable hypotheses on the dynamic intraday momentum effect are:

Hypothesis 1a. Following the disclosure of positive information, the intraday time-series predictability gets weaker than that of a normal day.

Hypothesis 1b. Following the disclosure of negative information, the intraday time-series predictability gets stronger than that of a normal day.

To verify the dynamic role of intraday momentum following informational disclosure, we rely on observed price jumps as the proxy for the ex post large informational shocks to the individual stocks. Jumps in asset price have long been considered as (unexpected) informational shocks (see Ball and Torous (1985), Johannes (2004), Maheu and McCurdy (2004), and Cremers et al. (2015) for theoretical justification). Jiang and Zhu (2017) also use price jumps as proxy of price-relevant informational arrivals and find a strong short-term momentum pattern at daily and weekly frequency. Therefore, we use intraday 5-minute returns and adopt the recursive intraday jump detection method based on Andersen et al. (2012) to identify positive and negative jump days. A positive (negative) jump day is defined as the date that has a positive (negative) jump return if there is only one intraday price jump during that day. In case there are more than one jump within the day, we calculate the (daily) cumulative jump return and define it as a positive (negative) jump day if the cumulative jump return is above (below) zero for that day. To save space, a full walk-through of the jump identification method is available in Appendix A.2.

\section{[ insert table 5 here ]}

Table 5 provides the summary statistics of the cumulative jump returns on positive and negative jump days respectively. For comparison purpose, we also present the corresponding statistics for all sample days. We adopt the same criteria as in prior sections by restricting to stocks with at least one-year available data (i.e., 244 trading days) in the analysis. The 
cumulative jump returns on positive jump days have an average value of $2.13 \%$ and a standard deviation of $1.59 \%$. Similarly, the cumulative jump returns on negative jump days have an average value of $-2.09 \%$ and a standard deviation of $1.55 \%$. In comparison, the average daily return over the sample period is only $0.04 \%$. Therefore, we confirm that price jumps in our sample represent substantial price movement within the day and may indicates valuable pricerelated information flows to the stock market. Looking across the 5\%, 25\%,50\%, 75\%, and 95\% quantile values, the cumulative jump returns on positive jump days ranges from $0.52 \%$ to $5.17 \%$, while the corresponding statistics on negative jump days ranges from $-5.55 \%$ to $-0.55 \%$. It seems that price jumps on positive jump days and negative jump days have analogous characteristics (i.e., the magnitude of the price jumps), except in different directions (i.e., the sign of the jump return). The only notable difference is that there are slightly more positive jump days than negative jump days during our sample period, as the ratio of the number of positive jump days to the total trading days is $14.09 \%$ compared to $10.73 \%$ for the ratio of negative jump days.

Empirically, we study the interaction between price jumps and intraday momentum via the following model specifications.

$$
\begin{aligned}
r_{\text {last }, t}=\alpha & +\beta_{1 s t} \times r_{1 s t, t}+\beta_{P J} \times P J \times r_{1 s t, t}+\beta_{N J} \times N J \times r_{1 s t, t} \\
& +\beta_{14: 30} \times r_{14: 30, t}+F E+\varepsilon_{t}
\end{aligned}
$$

and

$$
\begin{aligned}
r_{\text {last }, t}=\alpha & +\beta_{o v} \times r_{o v, t}+\beta_{P J} \times P J \times r_{o v, t}+\beta_{N J} \times N J \times r_{o v, t} \\
& +\beta_{14: 30} \times r_{14: 30, t}+F E+\varepsilon_{t}
\end{aligned}
$$

where $r_{\text {last }, t}, r_{1 s t, t}, r_{o v, t}, r_{14: 30, t}$, and $F E$ are defined similarly as in table 1 and 2. PJ (NJ) is the positive (negative) post-jump-day dummy which equals one if the prior trading day is detected as a positive (negative) jump day. It should be noted that the above two equations retain the same predictive flavor as before, because we are using the information set that is available before the last half-hour trading period at day $t$. The slope coefficients on the interaction terms $P J \times r_{1 s t, t}\left(P J \times r_{o v, t}\right)$ and $N J \times r_{1 s t, t}\left(N J \times r_{o v, t}\right)$ capture the incremental effect on intraday (overnight) momentum subsequent to the positive and negative jump days.

\section{[ insert table 6 here ]}

Table 6 presents the estimation results for the dynamic intraday momentum effect. The first two columns use the overnight returns to interact with the post-jump-day dummies with and 
without the penultimate half-hour return as the control variable in the model. Given that substantial favourable or detrimental information about the firm is revealed to the market (as manifested by the jump dummies), we document a striking asymmetric post-jump intraday momentum pattern: Following a positive jump day, the intraday momentum pattern over the next day is weakened as the slope coefficient on the interaction term is strongly negative with a value of -2.28 that is significantly at the $1 \%$ level. The total intraday momentum effect subsequent to a positive jump day is thus only $0.62(2.88-2.28)$, indicating a much weaker time-series predictability after positive information disclosure to the market. In a sharp contrast, however, subsequent to a negative jump day, the intraday momentum effect is strengthened greatly as the slope coefficient on the interaction term amounts to 2.53 which is highly significant at the $1 \%$ level. Thus, the total intraday momentum effect following negative jump days is approximately $5.41(2.88+2.53)$, implying a much stronger intraday predictability subsequent to a negative jump day than a normal day (with no price jumps). These dynamic patterns remain unchanged when we control the effect of return autocorrelation by including the penultimate half-hour returns in the regression model (column 2).

The next two columns in table 6 list the results when we use the first half-hour return as the predicting variable in the regression. As it stands, we find a similar asymmetric pattern that subsequent to a positive jump day, the intraday momentum is much weaker than following a normal trading day. In comparison, subsequent to a negative jump day, the overnight momentum effect intensified dramatically as compared to a normal trading day.

\section{[ insert table 7 here ]}

Table 7 provides further evidence on the asymmetric pattern of the post-jump intraday momentum effect. We generate alternative positive and negative post-jump dummies, which have the value of one for the one-day, two-day, and three-day event window following a positive or negative jump day. Therefore, the slope coefficients on the interaction term $P J \times r_{1 s t, t}\left(P J \times r_{o v, t}\right)$ and $N J \times r_{1 s t, t}\left(N J \times r_{o v, t}\right)$ capture the incremental effect on intraday (overnight) momentum averaged over these different post-jump event window. As expected, the averaged incremental effect due to the positive or negative informational shocks weakens over the longer event window, suggesting that the market has gradually incorporated the new price-relevant information over time. In other words, the intraday momentum effect gradually reverts back to its normal level subsequent to a positive or negative jump day. 
The above striking asymmetric pattern over the one-, two-, and three-day post-jump event window lends strong support to our testable hypotheses (Hypothesis 1a and 1b) that the intraday momentum effect is stronger following negative news about the firm. It is quite similar to the (cross-sectional) momentum pattern documented in Hong et al. (2000) who posit that bad news travels slowly in the financial market, and therefore, the cross-sectional momentum pattern is more pronounced after pessimistic information revealed to the market. Other studies have also found that market participants react differently to positive information and negative information (Pritamani \& Singal 2001; Jiang et al. 2011; Park \& Lee 2014; Brennan et al. 2015). Our evidence provides more direct support along this line, as it is more of the timeseries nature for one single asset. In other words, the asymmetric reaction to negative news exists for individual stocks, as it takes longer time for investors to digest the informational content of bad news, which leads to a more salient intraday time-series predictability.

\section{Individual Investor Account and Late-Informed Trading}

In principle, the intraday momentum could be attributed to both the (Bogousslavsky 2016) model of infrequent portfolio rebalancing and the Gao et al. (2018) model of late-informed trading near the market close. As is explained in the introduction section, China adopts a unique " $T+1$ trading rule", which prevents investors from selling stocks bought on the same day. This unique trading rule, however, goes counter to the settings of the infrequent portfolio rebalancing model, as traders who hold an excess position in the asset could not rebalance at the intraday frequency. The " $T+1$ trading rule" also precludes the rebalancing trading due to aversion of overnight risk in Elaut et al. (2018), as those who purchase the asset could not sell on the same day. In other words, the $T+1$ trading rule offers an ideal setting to empirically verify the (rich) predictions of the model of late-informed trading as suggested in Gao et al. $\underline{(2018)}$.

Within the model of late-informed trading, investors are heterogeneous in their ability to collect and interpret information. Those who have better skills to process the overnight information can act early in the morning trading session and even the pre-open call auction. However, for those who have less ability to process the overnight information or those who hesitate to trade until they confirm the precision of the overnight information, the last half-hour trading period stands for another important timing for them to utilize their (late-learned) information to trade, 
and thus exploiting the informational content. Based on these arguments, our main testable hypothesis on the late-informed trading is:

Hypothesis 2. Late-informed traders are relatively less experienced or skilful compared to those who trade mainly in the pre-open call auction and/or the early trading session.

To empirically validate the above hypothesis of the late-informed trading model, we rely on a proprietary investor account dataset obtained from a large brokerage firm in China. ${ }^{10}$ This unique dataset contains all the trading records in November 2014 for the members of individual investors that hold a brokerage account with the firm. We are aware that there are several limitations regarding our investor account data. First, the sampling period only spans for one month (i.e., November 2014). Second, it does not include institutional investors' trading activity. However, the bottom line is that analysing the investor account data provides us direct evidence on the late-informed trading model which otherwise would not be testable.

Panel A of Table 8 provides average trading behaviour of different investor types. During the 20 trading days in November 2014, there are totalling 120,608 active investors who have traded at least once during the sampling period. Among those active traders, only 7,896 investors have actually traded during the pre-open call auction, and we classify these active investors as earlyinformed traders. The relatively small number of early-informed traders is consistent with the relatively small transaction volume in the pre-open call auction. ${ }^{11}$

In comparison, we find that there are 18,281 individual investors who have never traded during the pre-open call auction and the opening half-hour trading period (i.e., 9:30 to 10:00). We classify these investors as late-informed investors, which is consistent with the definitions in the late-informed trading model. These late-informed traders forfeit the trading opportunity in the pre-open call auction session and also the opening half-hour trading session when the trading volume is the largest within the day. Interestingly, the number of investors who only trade after 10:00 is more than two times that who traded in the pre-open call auction, reinforces the importance of the late-informed trading in the Chinese stock market.

\footnotetext{
${ }^{10}$ The brokerage firm is a listed firm in China that provides a comprehensive securities-related services, including securities brokerage, investment consulting, financial advisory related to securities trading, and securities investment activities for investors, and it is rated as an A-class brokerage firm by China Securities Regulatory Commission (CSRC) in 2018.

${ }^{11}$ However, this ex post measure is probably an understatement as we only observe those who "successfully" transacted during the pre-open call market. We cannot rule out the possibility that some more investors could have submitted limit orders during the pre-open call auction, but not get those orders transacted.
} 
When we partition the number of trades within the day into subperiods, we again find strong systematic difference across the two investor groups (Panel A). Early-informed traders not only participate the pre-open call auction, they also concentrate their trades within the first halfhour continuous trading session, as $26.32 \%$ of their trades occurred between 9:30 and 10:00, while only $11.15 \%$ of their trades occurred in the last half-hour of day. Late-informed traders behaves differently: They not only forfeit the trading opportunity in the pre-open call auction and the first half-hour continuous trading session, but also concentrate their trades in the last half-hour trading session (i.e., 32.33\%). More generally, more than 70\% of their trades happen in the afternoon session (i.e., after 13:00).

To shed more light on the investor trading behaviour, we then compare the personal characteristics of all active traders, the early-informed traders, and the late-informed traders in Panel B of Table 8. It seems that early-informed traders are more likely to be experienced ones (defined as investors who have at least 10-year trading experience), as their proportion is $47.92 \%$. In comparison, the late-informed traders tend to be relatively inexperienced, as the proportion of having at least 10-trading experience is only $38.58 \%$. When compared with the proportion of experienced investors in all active investors, it is clear that early-informed (lateinformed) traders are more likely to be experienced (inexperienced) ones as demonstrated by the two-sample $t$-test with the total sample (i.e., all active investors).

Similarly, $20.71 \%$ of the early-informed traders are better educated, as compared to $18.49 \%$ in the late-informed group. The two-sample $t$-tests demonstrate that early-informed traders tend to have stronger educational background as compared to all active traders, while there is no systematic difference between late-informed traders and all active traders. Calvet et al. (2009) use households' educational background as a proxy of financial sophistication, and established an inverse relation with "financial mistakes". In that sense, we have good reasons to believe that early-informed (late-informed) traders are relatively more (less) sophisticated or skilled.

Other investor characteristics also reveal that early-informed traders are more likely to be male traders $(47.09 \%)$ than late-informed traders $(34.70 \%)$. Another systematic difference is that early-informed traders tend to have relatively high risk tolerance than late-informed traders. ${ }^{12}$ For robustness, we also perform logit regression to explain the probability of being an earlyinformed (late-informed) trader with the personal characteristics in Table 8. The coefficients

\footnotetext{
${ }^{12}$ Risk tolerance is measured through the required questionnaire when opening a client account with the brokerage firm.
} 
on trading experience, educational background (bachelor degree or higher) all have the expected signs and are highly significant at the $1 \%$ level (See Table A4 in appendix).

Overall, based on the unique investor-account data, we are able to uncover a number of interesting empirical patterns:

First, there exists a substantial fraction of late-informed traders (i.e., approximately $15 \%$ of all active traders) who concentrated their trading activity in the latter-half of the trading day, and in particular, the last half-hour of the continuous trading session.

Second, compared to early-informed traders, late-informed traders tend to be less experienced or sikllful (i.e., relatively less well-educated), which is consistent with the conjecture of the late-informed trading hypothesis (Hypothesis 2).

Overall, these salient features of investor heterogeneity in China are consistent with the predictions of the late-informed trading model that late-informed traders rely on the overnight returns or first half-hour returns, as one of the informational sources, to decide on the trading directions before the market closure.

\section{Robustness and Further Analyses}

\subsection{Firm-by-firm Evidence of Intraday Momentum using the First Half-hour Return}

In this subsection, we re-test the intraday return predictability of the first half-hour return based on firm-by-firm time-series regressions (see equation [3.1]). That is, we perform time-series regression for each individual firm in our dataset and report the aggregated firm-lever results.

Table A2. presents the aggregated firm-level evidence for the full sample and the three subsamples. When controlling for the effect of return autocorrelation (i.e., the penultimate halfhour return), the average value of the slope coefficient on the first half-hour return is 1.87 and the median value is slightly higher with 1.93. In addition, the average Newey West $t$-statistics amounts to 1.58 , which is statistically significant at the $10 \%$ level (based on the null hypothesis of the one-sided $t$-test that the slope coefficient is larger than zero). Among the 3,224 firms, more than $90 \%$ of the firms have a positive slope coefficient on the first half-hour return. Moreover, the slope coefficients that are statistically significant at the $1 \%, 5 \%$, and $10 \%$ level are more than $38 \%, 48 \%$, and $60 \%$, respectively, indicating strong intraday momentum effect 
at the firm level. ${ }^{13}$ We find similar patterns for the short-term return autocorrelation (i.e., the penultimate half-hour return) with the individual firms.

Table A2. also presents the aggregated firm-level evidence of the three subgroups (i.e., Main, SME, and ChiNext). After controlling the penultimate half-hour returns, we, again, document a strong intraday time-series predictability of the first half-hour return across the three subgroups. When examining the proportion of significant slope coefficients of the first halfhour return, there seems no discernible difference across the three subgroups. The only noticeable difference lies in the average explanatory power of the predictive model, which increases monotonically from $0.90 \%$ to $1.41 \%$ and to $1.65 \%$ for the Main, SME, and ChiNext board, respectively.

\subsection{Firm-by-firm Evidence of Intraday Momentum using the Overnight Return}

In this subsection, we re-perform the firm-by-firm time-series regressions to verify the intraday time-series predictability using the overnight return as the key predictor. Table A3. presents the aggregated firm-level evidence. As it stands, the overnight return remains a strong return predictor at the intraday frequency. When we control for the effect of the penultimate half-hour return, the overnight return still has a significant positive influence on the last half-hour return, as the average and median of the slope coefficient on overnight return amount to 2.81 and 2.78, respectively. Moreover, the average Newey West $t$-statistic is 1.78 (significant at the $5 \%$ level) and is higher than that of the penultimate half-hour return. More importantly, more than $92 \%$ of the listed firms have a positive slope coefficient on the overnight return, higher than that of the first half-hour return in Table A2. The slope coefficients on overnight return that are statistically significant at the $1 \%, 5 \%$, and $10 \%$ level are more than $45 \%, 55 \%$, and $67 \%$, respectively. ${ }^{14}$ This is consistent with the evidence in section 4 that the intraday momentum effect stems mainly from its overnight return component. In fact, comparing the magnitude of the corresponding slope coefficients (or adjusted R-square) in tables A.2. and A.3., it seems

\footnotetext{
${ }^{13}$ To be specific, the null hypothesis of intraday momentum is the slope coefficient of the first half-hour return is larger than zero. Therefore, we use the one-sided $t$ test to determine the significant level of each coefficient. $>$ $0 *,>0 * *$, and $>0 * * *$ denote that the Newey West $t$-statistic is above 1.28, 1.645, and 1.96, respectively (i.e., the $10 \%, 5 \%$, and $1 \%$ significance level).

${ }^{14}$ In unreported analysis, we find that little return predictability of the opening half-hour return. In fact, the average Newey West $t$-statistic of the opening half-hour return is only 0.39 , indicating that the return component from 9:30 to 10:00 offer little, if any, predictive power for the last half-hour return within the day. The percentage of firms that have significantly positive coefficient on the term $r_{10: 00, t}$ amount to around $8 \%, 13 \%$, and $21 \%$ at the $1 \%, 5 \%$, and $10 \%$ level, much lower than those of overnight return and penultimate half-hour return.
} 
that the overnight return component is more powerful in predicting the last half-hour return than the first half-hour return that includes the remaining return component from 9:30 to 10:00.

Table A3 also presents the aggregated firm-level evidence for overnight returns across the three subgroups. Again we find a robust pattern that the overnight component is the main driver of the intraday time-series predictor after controlling the penultimate half-hour returns. In general the overnight component has stronger predictability than its predecessor, the first halfhour return that contains the opening half-hour return component. The average explanatory power of the predictive model is in general larger than its counterpart with the first half-hour return, except for the case of ChiNext.

\subsection{Further Analyses}

We also perform two additional analyses to better understand the features of intraday momentum in China. ${ }^{15}$

First, we test the dynamic relation between intraday predictability and financial crises. Over the entire sample period, there are two notable crises which earn their names in the Chinese financial history. Namely, the 2007-2008 global financial crisis and the more recent 2015-2016 Chinese "stock disaster". Gao et al. (2018) and Elaut et al. (2018) both find that the intraday momentum effect strengthens during the financial crisis, which is reflected by the increasing magnitude of the slope coefficient and the explanatory power of the predicting model. To test the above notion, we generate a crisis dummy, denoted as $F C$, to test its interaction with the first half-hour return or the overnight return in predicting the last half-hour returns during the trading day. The crisis dummy equals one for the sample date ranges from 16 October 2007 to 18 September 2008 and from 12 Jun 2015 to 29 February 2016, and zero otherwise. The empirical results are similar to prior findings in Gao et al. (2018) and Elaut et al. (2018) that intraday momentum is more pronounced when market is in stressful states with increased return commonality. The total intraday momentum during crisis periods (i.e., the sum of the slope coefficient of the first half-hour return/overnight return and the slope coefficient on the interaction term) is more than doubled as compared to that on the normal days. Overall, we find strong evidence that the intraday (overnight) time-series momentum is much more intensified when the stock market crashes.

\footnotetext{
15 The empirical results on the further analyses are consolidated in the Internet Appendix.
} 
Second, we examine the time trend of intraday momentum. Gao et al. (2018) observe an upward trend indicating that the intraday time-series predictability is more pronounced in recent years in the US. We replicate the same rolling window exercise to test whether a similar time trend exists in the Chinese stock market. Based on trailing ten-year regressions, we find similar evidence that the predictive power of the first half-hour return or overnight return is getting stronger in more recent sample periods than earlier sample periods.

\section{Conclusion}

Based on a comprehensive high-frequency firm-level dataset that spans from 1996 to 2018, we re-test the intraday momentum pattern in the Chinese stock market, the largest emerging financial market. Our paper provides a number of new insights which extend the growing literature on intraday time-series momentum.

First, we provide compelling evidence that intraday time-series momentum exists at the firm level in the Chinese A-share market. The first half-hour return is a strong positive predictor for intraday return near market close (i.e., the last half-hour return).

Second, by partitioning the first half-hour return into its overnight component and the opening half-hour component, we find that the intraday momentum effect stems mainly from its overnight return component. This is consistent with the microstructure design in China that overnight information is incorporated via trading in the pre-open call auction. In comparison, the opening half-hour return is a much weaker price signal, as it probably incorporates multiple trading motives (such as informational driven, liquidity driven, and risk aversion). From a practical perspective, the overnight return is a more reliable return predictor than its predecessor, the first half-hour return.

Third, we document a strong asymmetric pattern, as the return predictability of the first halfhour or the overnight return is much stronger subsequent to days with negative jumps than with positive jumps. The striking asymmetric post-jump momentum pattern could be reconciled with a number of real-world mechanisms (i.e., frictions) such as biased managerial disclosure of good news versus bad news and the existence of stringent short-sales impediments. In other words, bad news travels slowly as indicated by stronger intraday momentum following large pessimist informational shocks.

Finally, we provide confirmatory evidence that there exists a substantial fraction of lateinformed traders (i.e., approximately $15 \%$ of all active traders) who concentrated their trading 
activity in the latter-half of the trading day, and in particular, near market closure. Consistent with the predictions of late-informed trading model, late-informed traders have relatively less trading experience and educational background than those who tend to trade in the pre-open call market (i.e., early-informed traders). Therefore, the last half-hour trading period stands for an important timing for those late-informed to utilize their (late-learned) information. 


\section{Table 1. Intraday momentum with the first half-hour return}

The table presents the estimation results of the panel regressions with fixed effects. The dependent variable is the last half-hour return of the trading day. $r_{1 s t, t}$ denotes the first halfhour return calculated using the closing price of the prior trading day and the stock price at 10:00 of the current trading day, $r_{14: 30, t}$ denotes the penultimate half-hour return calculated using the stock prices at 14:00 and 14:30 of the current trading day, $\alpha$ denotes the intercept term in the regression, $R^{2}$ denotes the adjusted R-squared, Obs. denotes the number of observations in each regression, and Firms denotes the number of firms in the regression. The standard error of each coefficient is reported in parenthesis. All values reported are in percentages except for Obs. and Firms. Significance at the 1\%, 5\%, and $10 \%$ level is denoted as $* * *, * *$, and $*$, respectively.

\begin{tabular}{lrrr}
\hline & \multicolumn{1}{c}{$(\mathbf{1})$} & $\mathbf{( 2 )}$ & $\mathbf{( 3 )}$ \\
\cline { 2 - 4 }$r_{1 s t, t}$ & $1.921 * * *$ & & $1.832 * * *$ \\
& $(0.0167)$ & & $(0.0167)$ \\
$r_{14: 30, t}$ & & $(0.163 * * *$ & $6.022^{* * *}$ \\
& & $0.0324 * * *$ & $(0.0366)$ \\
$\alpha$ & $0.0339 * * *$ & $(0.0003)$ & $0.0335 * * *$ \\
& $(0.0003)$ & 0.37 & $(0.0003)$ \\
$R^{2}$ & 0.16 & $7,787,027$ & 0.51 \\
Obs. & $7,787,027$ & 3,224 & $7,787,027$ \\
Firms & 3,224 & & 3,224 \\
\hline
\end{tabular}




\section{Table 2: Subsample analysis of intraday momentum with the first-half hour return}

The table presents the estimation results of the panel regressions with fixed effects. The dependent variable is the last half-hour return of the trading day. Main board includes all A-shares listed in the Shanghai Stock Exchange and those in the main board of the Shenzhen Stock Exchange. SME board includes all A-shares listed in the SME board of the Shenzhen Stock Exchange. ChiNext includes all A-shares listed in the ChiNext board of the Shenzhen Stock Exchange. $r_{1 s t, t}$ denotes the first half-hour return calculated using the closing price of the prior trading day and the stock price at 10:00 of the current trading day, $r_{14: 30, t}$ denotes the penultimate half-hour return calculated using the stock prices at 14:00 and 14:30 of the current trading day, $\alpha$ denotes the intercept term in the regression, $R^{2}$ denotes the adjusted R-squared, $O b s$. denotes the number of observations in each regression, and Firms denotes the number of firms in the regression. The standard error of each coefficient is reported in parenthesis. All values reported are in percentages except for Obs. and Firms. Significance at the 1\%, 5\%, and 10\% level is denoted as ***, **, and *, respectively.

\begin{tabular}{|c|c|c|c|c|c|c|c|c|c|}
\hline & & Main & & & SME & & & ChiNext & \\
\hline & (1) & (2) & (3) & (1) & $(2)$ & (3) & (1) & (2) & (3) \\
\hline$r_{1 s t, t}$ & $1.73 * * *$ & & $1.65 * * *$ & $2.27 * * *$ & & $2.14 * * *$ & $2.35 * * *$ & & $2.20 * * *$ \\
\hline & $(0.0205)$ & & $(0.0205)$ & $(0.037)$ & & $(0.037)$ & $(0.047)$ & & $(0.047)$ \\
\hline$r_{14: 30, t}$ & & $5.41 * * *$ & $5.30 * * *$ & & $7.55 * * *$ & $7.36 * * *$ & & $8.63 * * *$ & $8.40 * * *$ \\
\hline & & $(0.0436)$ & $(0.0436)$ & & $(0.082)$ & $(0.082)$ & & (0.117) & (0.117) \\
\hline$\alpha$ & $0.0469 * * *$ & $0.0453 * * *$ & $0.0465 * * *$ & $0.0096 * * *$ & $0.0079 * * *$ & $0.0093 * * *$ & $-0.0169 * * *$ & $-0.0154 * * *$ & $-0.0158 * * *$ \\
\hline & $(0.0003)$ & $(0.0003)$ & $(0.0003)$ & $(0.0007)$ & $(0.0007)$ & (0.0007) & (0.0011) & (0.0011) & (0.0011) \\
\hline$R^{2}$ & 0.12 & 0.28 & 0.39 & 0.24 & 0.57 & 0.78 & 0.31 & 0.76 & 1.03 \\
\hline Obs. & $5,563,999$ & $5,563,999$ & $5,563,999$ & $1,503,005$ & $1,503,005$ & $1,503,005$ & 720,023 & 720,023 & 720,023 \\
\hline Firms & 1,738 & 1,738 & 1,738 & 852 & 852 & 852 & 634 & 634 & 634 \\
\hline
\end{tabular}




\section{Table 3. Overnight component versus the opening half-hour component}

The table presents the estimation results of the panel regressions with fixed effects. The dependent variable is the last half-hour return of the trading day. $r_{o v, t}$ denotes the overnight return calculated using the close price of the prior trading day and the opening price at 9:30 of the current trading day, $r_{10: 00, t}$ denotes the opening half-hour return calculated using the stock prices at 9:30 and 10:00 of the current trading day, $r_{14: 30, t}$ denotes the penultimate half-hour return calculated using the stock prices at 14:00 and 14:30 of the current trading day, $\alpha$ denotes the intercept term in the regression, $R^{2}$ denotes the adjusted R-squared, Obs. denotes the number of observations in each regression, and Firms denotes the number of firms in the regression. The standard error of each coefficient is reported in parenthesis. All values reported are in percentages except for Obs. and Firms. Significance at the 1\%, 5\%, and $10 \%$ level is denoted as $* * *, * *$, and $*$, respectively.

\begin{tabular}{|c|c|c|c|c|}
\hline & (1) & (2) & (3) & (4) \\
\hline$r_{o v, t}$ & $\begin{array}{r}2.881 * * * \\
(0.0216)\end{array}$ & $\begin{array}{r}2.922 * * * \\
(0.0217)\end{array}$ & $\begin{array}{r}2.780 * * * \\
(0.0216)\end{array}$ & $\begin{array}{r}2.812 * * * \\
(0.0216)\end{array}$ \\
\hline$r_{10: 00, t}$ & & $\begin{array}{r}0.641 * * * \\
(0.0243)\end{array}$ & & $\begin{array}{r}0.566 * * * \\
(0.0243)\end{array}$ \\
\hline$r_{14: 30, t}$ & & & $\begin{array}{r}6.021 * * * \\
(0.0365)\end{array}$ & $\begin{array}{r}6.012 * * * \\
(0.0365)\end{array}$ \\
\hline$\alpha$ & $\begin{array}{r}0.036 * * * \\
(0.0003)\end{array}$ & $\begin{array}{r}0.035 * * * \\
(0.0003)\end{array}$ & $\begin{array}{r}0.035 * * * \\
(0.0003)\end{array}$ & $\begin{array}{r}0.035 * * * \\
(0.0003)\end{array}$ \\
\hline$R^{2}$ & 0.22 & 0.23 & 0.57 & 0.58 \\
\hline Obs. & $7,787,027$ & $7,787,027$ & $7,787,027$ & $7,787,027$ \\
\hline Firms & 3,224 & 3,224 & 3,224 & 3,224 \\
\hline
\end{tabular}




\section{Table 4. Overnight return versus alternative opening returns}

The table presents the estimation results of the panel regressions with fixed effects. The dependent variable is the last half-hour return of the trading day. $r_{o v, t}$ denotes the overnight return calculated using the close price of the prior trading day and the opening price at 9:30 of the current trading day. The alternative versions of the opening returns are $r_{9: 35, t}, r_{9: 40, t}, r_{9: 45, t}$, $r_{9: 50, t}, r_{9: 55, t}$, and $r_{10: 00, t}$, which are the intraday returns calculated using the opening price and the stock prices at 9:35, 9:40, 9:45, 9:50, 9:55, and 10:00 of the trading day, respectively. $r_{14: 30, t}$ denotes the penultimate half-hour return calculated using the stock prices at 14:00 and 14:30 of the current trading day, $\alpha$ denotes the intercept term in the regression, $R^{2}$ denotes the adjusted R-squared, Obs. denotes the number of observations in each regression, and Firms denotes the number of firms in the regression. The standard error of each coefficient is reported in parenthesis. All values reported are in percentages except for Obs. and Firms. Significance at the $1 \%, 5 \%$, and $10 \%$ level is denoted as $* * *, * *$, and $*$, respectively.

\begin{tabular}{|c|c|c|c|c|c|c|}
\hline & (1) & (2) & (3) & (4) & (5) & (6) \\
\hline$r_{o v, t}$ & $\begin{array}{l}2.78 * * * \\
(0.0216)\end{array}$ & $\begin{array}{l}2.78 * * * \\
(0.0216)\end{array}$ & $\begin{array}{l}2.79 * * * \\
(0.0216)\end{array}$ & $\begin{array}{l}2.79 * * * \\
(0.0216)\end{array}$ & $\begin{array}{l}2.79 * * * \\
(0.0216)\end{array}$ & $\begin{array}{l}2.81 * * * \\
(0.0216)\end{array}$ \\
\hline$r_{9: 35, t}$ & $\begin{array}{c}-0.077 * \\
(0.0424)\end{array}$ & & & & & \\
\hline$r_{9: 40, t}$ & & $\begin{array}{c}-0.058 * \\
(0.0336)\end{array}$ & & & & \\
\hline$r_{9: 45, t}$ & & & $\begin{array}{r}0.300 * * * \\
(0.0297)\end{array}$ & & & \\
\hline$r_{9: 50, t}$ & & & & $\begin{array}{r}0.421 * * * \\
(0.0273)\end{array}$ & & \\
\hline$r_{9: 55, t}$ & & & & & $\begin{array}{r}0.387 * * * \\
(0.0254)\end{array}$ & \\
\hline$r_{10: 00, t}$ & & & & & & $\begin{array}{r}0.566 * * * \\
(0.0243)\end{array}$ \\
\hline$r_{14: 30, t}$ & $\begin{array}{l}6.02 * * * \\
(0.0365)\end{array}$ & $\begin{array}{c}6.02 * * * \\
(0.0365)\end{array}$ & $\begin{array}{l}6.02 * * * \\
(0.0365)\end{array}$ & $\begin{array}{l}6.02 * * * \\
(0.0365)\end{array}$ & $\begin{array}{l}6.02 * * * \\
(0.0365)\end{array}$ & $\begin{array}{l}6.01 * * * \\
(0.0365)\end{array}$ \\
\hline$\alpha$ & $\begin{array}{r}0.0352 * * * \\
(0.0003)\end{array}$ & $\begin{array}{r}0.0352 * * * \\
(0.0003)\end{array}$ & $\begin{array}{r}0.0352 * * * \\
(0.0003)\end{array}$ & $\begin{array}{r}0.0351^{* * * *} \\
(0.0003)\end{array}$ & $\begin{array}{r}0.0351 * * * \\
(0.0003)\end{array}$ & $\begin{array}{r}0.0351 * * * * \\
(0.0003)\end{array}$ \\
\hline$R^{2}$ & 0.57 & 0.57 & 0.57 & 0.57 & 0.57 & 0.58 \\
\hline Obs. & $7,787,027$ & $7,787,027$ & $7,787,027$ & $7,787,027$ & $7,787,027$ & $7,787,027$ \\
\hline Firms & 3,224 & 3,224 & 3,224 & 3,224 & 3,224 & 3,224 \\
\hline
\end{tabular}


Table 5. Summary statistics about jump days

The table presents the summary statistics of the cumulative daily positive jump return $\left(R E T_{P J}\right)$, cumulative daily negative jump return $\left(R E T_{N J}\right)$ and cumulative daily return $(R E T)$. It reports the mean and standard deviation of the variables, and their values at the 5\%,25\%,50\%, 75\%, and $95 \%$ quantiles. Ratio denotes the ratio of the number of days with positive jumps / negative jumps to the total trading days.

\begin{tabular}{|c|c|c|c|c|c|c|c|c|}
\hline & Mean & Std. & $5 \%$ & $25 \%$ & $50 \%$ & $75 \%$ & $95 \%$ & Ratio \\
\hline$R E T_{P J}$ & 2.133 & 1.590 & 0.521 & 1.091 & 1.682 & 2.627 & 5.167 & $14.089 \%$ \\
\hline$R E T_{N J}$ & -2.094 & 1.550 & -5.548 & -2.691 & -1.659 & -1.078 & -0.549 & $10.731 \%$ \\
\hline$R E T$ & 0.044 & 3.160 & -5.231 & -1.511 & 0.076 & 1.575 & 5.336 & --- \\
\hline
\end{tabular}




\section{Table 6. Intraday momentum and price jumps}

The table presents the estimation results of the panel regressions with fixed effects. The dependent variable is the last half-hour return of the trading day. $r_{1 s t, t}$ denotes the first halfhour return, calculated using the closing price of the prior trading day and the stock price at 10:00 of the current trading day, $r_{o v, t}$ denotes the overnight return calculated using the close price of the prior trading day and the opening price at 9:30 of the current trading day, $r_{14: 30, t}$ denotes the penultimate half-hour return, calculated from the stock prices from 14.00 to 14.30 of the current trading day. $P J$ and $N J$ are dummy variables, which equal 1 if the prior trading day is detected as a positive and a negative jump day, respectively. $\alpha$ denotes the intercept term in the regression, $R^{2}$ denotes the adjusted R-squared, $O b s$. denotes the number of observations in each regression, and Firms denotes the number of firms in the regression. The standard error of each coefficient is reported in parenthesis. All values reported are in percentages except for Obs. and Firms. Significance at the 1\%, 5\%, and 10\% level is denoted as ***, **, and *, respectively.

\begin{tabular}{|c|c|c|c|c|}
\hline & \multicolumn{2}{|c|}{ Overnight return } & \multicolumn{2}{|c|}{ First half-hour return } \\
\hline & (1) & (2) & (1) & $(2)$ \\
\hline$r_{1 s t, t}$ & & & $\begin{array}{r}1.811 * * * \\
(0.0214)\end{array}$ & $\begin{array}{r}1.722 * * * \\
(0.0214)\end{array}$ \\
\hline$r_{o v, t}$ & $\begin{array}{r}2.882 * * * \\
(0.0292)\end{array}$ & $\begin{array}{r}2.781 * * * \\
(0.0292)\end{array}$ & & \\
\hline$P J \times r_{1 s t, t}$ & & & $\begin{array}{r}-1.683 * * * \\
(0.0430)\end{array}$ & $\begin{array}{r}-1.621 * * * \\
(0.0430)\end{array}$ \\
\hline$P J \times r_{o v, t}$ & $\begin{array}{r}-2.284 * * * \\
(0.0540)\end{array}$ & $\begin{array}{r}-2.182 * * * \\
(0.0539)\end{array}$ & & \\
\hline$N J \times r_{1 s t, t}$ & & & $\begin{array}{r}2.642 * * * \\
(0.0455)\end{array}$ & $\begin{array}{r}2.522 * * * \\
(0.0455)\end{array}$ \\
\hline$N J \times r_{o v, t}$ & $\begin{array}{c}2.532 * * * \\
(0.0551)\end{array}$ & $\begin{array}{c}2.401 * * * \\
(0.0550)\end{array}$ & & \\
\hline$r_{14: 30, t}$ & & $\begin{array}{r}5.973 * * * \\
(0.0365)\end{array}$ & & $\begin{array}{r}5.971 * * * \\
(0.0366)\end{array}$ \\
\hline$\alpha$ & $\begin{array}{c}0.041 * * * \\
(0.0003)\end{array}$ & $\begin{array}{r}0.041 * * * \\
(0.0003)\end{array}$ & $\begin{array}{r}0.041 * * * \\
(0.0003)\end{array}$ & $\begin{array}{r}0.040 * * * \\
(0.0003)\end{array}$ \\
\hline$R^{2}$ & 0.30 & 0.65 & 0.26 & 0.60 \\
\hline Obs. & $7,787,027$ & $7,787,027$ & $7,787,027$ & $7,787,027$ \\
\hline Firms & 3,224 & 3,224 & 3,224 & 3,224 \\
\hline
\end{tabular}




\section{Table 7. Post-jump Effect}

The table presents the estimation results of the panel regressions with fixed effects. The dependent variable is the last half-hour return of the trading day. $r_{1 s t, t}$ denotes the first halfhour return, calculated using the closing price of the prior trading day and the stock price at 10:00 of the current trading day, $r_{o v, t}$ denotes the overnight return calculated using the close price of the prior trading day and the opening price at 9:30 of the current trading day, $r_{14: 30, t}$ denotes the penultimate half-hour return, calculated from the stock prices from 14.00 to 14.30 of the current trading day. $P J$ and $N J$ are the post-jump dummy which equals 1 over the one-, two-, three-day event window subsequent to the positive and negative jump days, respectively. $\alpha$ denotes the intercept term in the regression, $R^{2}$ denotes the adjusted R-squared, Obs. denotes the number of observations in each regression, and Firms denotes the number of firms in the regression. The standard error of each coefficient is reported in parenthesis. All values reported are in percentages except for Obs. and Firms. Significance at the 1\%, 5\%, and $10 \%$ level is denoted as $* * *, * *$, and $*$, respectively.

\begin{tabular}{|c|c|c|c|c|c|c|}
\hline & \multicolumn{3}{|c|}{ Panel A: Overnight Return } & \multicolumn{3}{|c|}{ Panel B: First Half-hour Return } \\
\hline & One-day & Two-day & Three-day & One-day & Two-day & Three-day \\
\hline$r_{1 s t, t}$ & & & & $\begin{array}{c}1.72 * * * \\
(0.0214)\end{array}$ & $\begin{array}{r}1.62 * * * \\
(0.0234)\end{array}$ & $\begin{array}{r}1.47 * * * \\
(0.0252)\end{array}$ \\
\hline$r_{o v, t}$ & $\begin{array}{l}2.78 * * * \\
(0.0292)\end{array}$ & $\begin{array}{l}2.51 * * * \\
(0.0260)\end{array}$ & $\begin{array}{c}2.38 * * * \\
(0.0264)\end{array}$ & & & \\
\hline$P J \times r_{1 s t, t}$ & & & & $\begin{array}{c}-1.62 * * * \\
(0.0430)\end{array}$ & $\begin{array}{r}-1.09 * * * \\
(0.0367)\end{array}$ & $\begin{array}{c}-0.66 * * * \\
(0.0344)\end{array}$ \\
\hline$P J \times r_{o v, t}$ & $\begin{array}{c}-2.18 * * * \\
(0.0539)\end{array}$ & $\begin{array}{c}-0.99 * * * \\
(0.0334)\end{array}$ & $\begin{array}{c}-0.59 * * * \\
(0.0304)\end{array}$ & & & \\
\hline$N J \times r_{1 s t, t}$ & & & & $\begin{array}{l}2.52 * * * \\
(0.0455)\end{array}$ & $\begin{array}{c}2.08 * * * \\
(0.0386)\end{array}$ & $\begin{array}{r}1.87 * * * \\
(0.0357)\end{array}$ \\
\hline$N J \times r_{o v, t}$ & $\begin{array}{l}2.40 * * * \\
(0.0550)\end{array}$ & $\begin{array}{l}2.09 * * * \\
(0.0361)\end{array}$ & $\begin{array}{l}1.86 * * * \\
(0.0329)\end{array}$ & & & \\
\hline$r_{14: 30, t}$ & $\begin{array}{r}5.97 * * * \\
(0.0365)\end{array}$ & $\begin{array}{l}5.97 * * * \\
(0.0365)\end{array}$ & $\begin{array}{r}5.98 * * * \\
(0.0365)\end{array}$ & $\begin{array}{c}5.97 * * * \\
(0.0366)\end{array}$ & $\begin{array}{r}5.97 * * * \\
(0.0366)\end{array}$ & $\begin{array}{r}5.98 * * * \\
(0.0366)\end{array}$ \\
\hline$\alpha$ & $\begin{array}{r}0.041 * * * \\
(0.0003)\end{array}$ & $\begin{array}{r}0.0392 * * * \\
(0.0003)\end{array}$ & $\begin{array}{r}0.0379 * * * \\
(0.0003)\end{array}$ & $\begin{array}{r}0.040 * * * \\
(0.0003)\end{array}$ & $\begin{array}{r}0.0378 * * * \\
(0.0003)\end{array}$ & $\begin{array}{r}0.0365^{* * *} \\
(0.0003)\end{array}$ \\
\hline$R^{2}$ & 0.65 & 0.64 & 0.62 & 0.60 & 0.58 & 0.56 \\
\hline Obs. & $7,787,027$ & $7,787,027$ & $7,787,027$ & $7,787,027$ & $7,787,027$ & $7,787,027$ \\
\hline Firms & 3,224 & 3,224 & 3,224 & 3,224 & 3,224 & 3,224 \\
\hline
\end{tabular}




\section{Table 8. Individual Investor Accounts and Trading Activities, November 2014}

The table reports the individual investor accounts by types. All investors denote all the individual investors who have traded during the sample month; Early-informed refers to the individual investors who have traded in the pre-open call auction; Late-informed refers to the individual investors who have never traded in the pre-open call auction and the opening halfhour during the morning session. Panel A reports, for each investor type, the number of investors, number of stocks traded, number of total trades, and the ratio of the number of trades within each trading period and the total number of trades averaged across days. Panel B reports the characteristics of the different investor types. Two-sample $t$-statistics are reported in parenthesis. Significance at the $1 \%, 5 \%$, and $10 \%$ level is denoted as ***, **, and *, respectively.

Panel A. Proportion of the Number of Trades

\begin{tabular}{lrrr}
\hline & All Investors & Early-informed & Late-informed \\
\cline { 2 - 4 } Number of investors & 120,608 & 7,896 & 18,281 \\
Number of stocks traded & 2,411 & 2,409 & 2,397 \\
Number of trades & $2,890,937$ & 576,715 & 127,685 \\
Proportion of trades $(\boldsymbol{\%})$ & & & \\
$\quad$ Pre-open call & 0.56 & $\mathbf{2 . 8 1}$ & -- \\
$>09: 30 \&<=10: 00$ & 21.90 & 26.32 & - \\
$>10: 00 \&<=10: 30$ & 14.11 & 13.95 & 10.13 \\
$>10: 30 \&<=11: 00$ & 10.70 & 10.17 & 9.71 \\
$>11: 00 \&<=11: 30$ & 8.42 & 8.02 & 8.57 \\
$>13: 00 \&<=13: 30$ & 10.15 & 9.55 & 11.91 \\
$>13: 30 \&<=14: 00$ & 10.04 & 8.99 & 12.67 \\
$>14: 00 \&<=14: 30$ & 10.42 & 9.04 & 14.68 \\
$>14: 30 \&<=15: 00$ & 13.71 & 11.15 & $\mathbf{3 2 . 3 3}$ \\
$\quad$ Total & 100 & 100 & 100 \\
\hline
\end{tabular}

Panel B. Characteristics by Investor Types

\begin{tabular}{lrrr}
\hline & All Investors & Early-informed & Late-informed \\
\cline { 2 - 4 } $\begin{array}{l}\text { Proportion with trading } \\
\text { experience > 10 years }\end{array}$ & $41.59 \%$ & $47.92 \%$ & $38.58 \%$ \\
& & $6.34 \% * * *$ & $-3.01 \% * * *$ \\
& & $(11.06)$ & $(-7.70)$ \\
$\begin{array}{l}\text { Proportion with Bachelor } \\
\text { degree or above }\end{array}$ & $18.64 \%$ & $20.71 \%$ & $18.49 \%$ \\
& & $2.06 \% * * *$ & $-0.15 \%$ \\
$\begin{array}{l}\text { Proportion of male } \\
\text { investors }\end{array}$ & & $(4.47)$ & $(-0.50)$ \\
& $38.98 \%$ & $47.09 \%$ & $34.70 \%$ \\
Proportion with high-risk & & $8.11 \% * * *$ & $-4.28 \% * * *$ \\
tolerance & $20.95 \%$ & $(14.14)$ & $(-11.20)$ \\
& & $27.96 \%$ & $17.79 \%$ \\
& & $7.01 \% * * *$ & $-3.16 \% * * *$ \\
\end{tabular}




\section{Appendix}

\section{A.1. Variables Definition}

\begin{tabular}{|c|c|}
\hline Variables & Description \\
\hline$r_{\text {last }}$ & $\begin{array}{l}\text { The last half-hour return calculated using the stock prices at 14:30 and 15:00 } \\
\text { (i.e., market close) of the current trading day. }\end{array}$ \\
\hline$r_{1 s t}$ & $\begin{array}{l}\text { The first half-hour return calculated using the close price of the prior trading day } \\
\text { and the stock price at 10:00 of the current trading day. }\end{array}$ \\
\hline$r_{14: 30}$ & $\begin{array}{l}\text { The penultimate half-hour return calculated using the stock prices at 14:00 and } \\
\text { 14:30 of the current trading day. }\end{array}$ \\
\hline$r_{o v}$ & $\begin{array}{l}\text { The overnight return calculated using the close price of the prior trading day and } \\
\text { the opening price at 9:30 of the current trading day (i.e., close-to-open). }\end{array}$ \\
\hline$r_{10: 00}$ & $\begin{array}{l}\text { The opening half-hour return calculated using the stock prices at 9:30 and 10:00 } \\
\text { of the current trading day, excluding overnight returns. }\end{array}$ \\
\hline$P J$ & $\begin{array}{l}\text { Positive jump dummy that equals } 1 \text { if the prior trading day is a positive jump } \\
\text { day. }\end{array}$ \\
\hline NJ & $\begin{array}{l}\text { Negative jump dummy that equals } 1 \text { if the prior trading day is a negative jump } \\
\text { day. }\end{array}$ \\
\hline$F C$ & $\begin{array}{l}\text { Financial crises dummy that equals } 1 \text { if the date ranges from 16th October } 2007 \\
\text { to } 18 \text { th September } 2008 \text { or from 12th June } 2015 \text { to 29th February } 2016 .\end{array}$ \\
\hline$F C_{1}$ & $\begin{array}{l}\text { Crisis dummy that equals } 1 \text { if the date ranges from 16th October } 2007 \text { to } 18 \text { th } \\
\text { September } 2008 \text {. }\end{array}$ \\
\hline$F C_{2}$ & $\begin{array}{l}\text { Crisis dummy that equals } 1 \text { if the date ranges from 12th June } 2015 \text { to } 29 \text { th } \\
\text { February } 2016 .\end{array}$ \\
\hline
\end{tabular}




\section{A.2. Jump Detection Method}

We assume a jump-diffusion process for the underlying (logarithmic) price, $p_{t}$, which is of the following form:

$$
d p_{t}=\mu_{t} d t+\sigma_{t} d W_{t}+d J_{t}
$$

where $\mu_{t}$ is the drift, $\sigma_{t}$ the diffusion parameter, $W_{t}$ the Brownian motion, and $\mathrm{J}_{\mathrm{t}}$ the jump process at time $t$. Given the dynamics of the underlying process, Barndorff-Nielsen and Shephard $(2004, \underline{2006)}$ states theoretically that the quadratic variation $(Q V)$ for the price process can be decomposed into a continuous volatility component, known as integrated variance $(I V)$, and a jump component. In finite samples, the quadratic variation is usually approximated by the realized variance $(R V)$, a non-parametric measure. For the sample counterparty of the integrated variance, we follow the suggestions in Andersen et al. (2012) by adopting the $M e d R V$ measure, which provides better finite sample robustness (in the case of stale prices) and asymptotic efficiency than any Multi-power variation (MPV) measures (such as bipower variation). Following Andersen et al. (2012), the two non-parametric measures, $R V$ and $M e d R V$, are computed as follows:

$$
\begin{gathered}
R V \equiv \sum_{j=1}^{M} r_{j}^{2} \\
M e d R V \equiv \frac{\pi}{6-4 \sqrt{3}+\pi}\left(\frac{M}{M-2}\right) \sum_{j=3}^{M} \operatorname{med}\left(\left|r_{j}\right|,\left|r_{j-1}\right|,\left|r_{j-2}\right|\right)^{2}
\end{gathered}
$$

where $r_{j}$ is the $j t h$ intraday return and $M$ the total number of intraday return intervals within a single day. For brevity, we have omitted the subscript for the daily indexation.

Based on the quadratic variation theory (Barndorff-Nielsen \& Shephard 2004, 2006), the difference between $R V$ and $M e d R V$ provides a consistent estimation of the jump component as $M$ tends to infinity. ${ }^{16}$ To detect the trading days with significant jump(s), we rely on the ratio test statistics $(Z)$ based on its good finite sample property (Huang \& Tauchen 2005):

$$
Z=M^{\frac{1}{2}} \frac{[R V-M e d R V] \times R V^{-1}}{\left[\left(\mu_{1}^{-4}+2 \mu_{1}^{-2}-5\right) \times \max \left\{1, M e d R Q \times M e d R V^{-2}\right\}\right]^{\frac{1}{2}}}
$$

with the estimator of the higher-order quarticity, $\operatorname{MedRQ}$, defined as

$$
\operatorname{MedRQ} \equiv \frac{3 \pi M}{9 \pi+72-52 \sqrt{3}}\left(\frac{M}{M-2}\right) \sum_{j=3}^{M} \operatorname{med}\left(\left|r_{j}\right|,\left|r_{j-1}\right|,\left|r_{j-2}\right|\right)^{4}
$$

In practice, the test needs to be implemented for certain stringent significant levels in order to avoid the detection of spurious jumps. Following the literature, we set the significant level to $\alpha=0.01 \%$ (Beine et al. 2007; Evans 2011; Bajgrowicz et al. 2015). Throughout the paper, we adopt the 5-min sampling frequency to alleviate the potential influence of market microstructure frictions, which might bias the measures of $R V$ and $M e d R V$.

\section{The Recursive Intraday Jump Detection Scheme}

\footnotetext{
${ }^{16}$ For the mathematical proof, see theorem 2 in Barndorff-Nielsen and Shephard (2004).
} 
When the null hypothesis that there is no jump (within a day) is rejected based on the ratio test statistic, we apply a sequential intraday jump detection scheme to identify the intraday jumps and their timing within the day. That is, if the ratio statistic $(Z)$ is significant at day $i$, we first assume that only one intraday return contributes to the significant $Z$-stat and then proceed as follows:

Step 1: We record the significant ratio statistic $Z_{i}$ and extract the series of the $M$ intraday (geometric) returns $\left\{r_{i, 1}, r_{i, 2}, \ldots, r_{i, M}\right\}$ within day $i$.

Step 2: For each intraday return $r_{i, j}(j=1,2, \ldots, M)$ at day $i$, we generate a modified series $\left\{r_{i, 1}, r_{i, 2}, \ldots, r_{i, \text { median }} \ldots, r_{i, M}\right\}$ by replacing the $j t h$ element with the median of the intraday returns (denoted as $r_{i, \text { median }}$ ) in day $i$, while keeping the rest unchanged. We then recalculate the corresponding $Z$-stat (denoted as $Z_{i}^{(J)}$ ) for the $M$ "new" intraday return series to obtain a "sample" of $M$ revised $Z$-stats $\left\{Z_{i}^{(1)}, Z_{i}^{(2)}, \ldots, Z_{i}^{(M)}\right\}$ for day $i$.

Step 3: We calculate the differences between the original $Z$-stat and (each of) the new $Z$ statistics $\left\{Z_{i}-Z_{i}^{(1)}, Z_{i}-Z_{i}^{(2)}, \ldots, Z_{i}-Z_{i}^{(M)}\right\}$. The significant jump return $r_{i, J}$ is identified when the following mathematical expression achieves its maximum.

$$
I_{\left\{Z_{i}>\Phi_{1-\alpha}\right\}}\left(\max _{J \in\{1,2, \ldots, M\}} Z_{i}-Z_{i}^{(J)}\right)
$$

Step 4: We retain the revised $Z$-stat $\left(Z_{i}^{(J)}\right)$ identified in Step 3. If $Z_{i}^{(J)}$ is less than the preset critical value, we conclude that there is only one jump on day $i$. However, if it still exceeds the critical value, we then replace the identified jump observation with $r_{i \text {,median }}$, and start over again from Step 1 to Step 4 to identify the second intraday jump on day $i$.

The above recursive procedure continues until all the intraday jumps within day $i$ are identified. In this way, we are able to extract all the intraday jumps during the sample period. Similar sequential jump detection methods are also used in Andersen et al. (2010), Jiang and Oomen (2008) and Jiang et al. (2011). The major difference between their procedure and ours is that we rely on the MedRV measure for the jump tests, while they use bipower variation or other alternatives to approximate the integrated variance in finite sample. To ensure that the identified jump returns are not spurious due to bid-ask bounces, we follow the additional procedure of Jiang and Zhu (2017) by filtering out the jump returns which are less than twice the tick size. 


\section{Table A1. Summary Statistics of the Chinese A-Share Market}

The table provides the breakdown of the summary statistics of the Chinese A-shares. Main board includes all A-shares listed in the Shanghai Stock Exchange and A-shares in the Main board of the Shenzhen Stock Exchange. SME board includes all A-shares listed in the SME board of the Shenzhen Stock Exchange. ChiNext includes all A-shares listed in the ChiNext board of the Shenzhen Stock Exchange. Total market capitalization is measured in billions of Chinese yuan, total number of shares outstanding is measured in billions, and total trading volume is measured in 100 millions of Chinese yuan.

\begin{tabular}{|c|c|c|c|c|c|c|c|c|c|c|c|c|}
\hline & \multicolumn{3}{|c|}{ Number of Stocks } & \multicolumn{3}{|c|}{ Market Cap. $\left(\times 10^{9}\right)$} & \multicolumn{3}{|c|}{ Shares Outstanding $\left(\times 10^{9}\right)$} & \multicolumn{3}{|c|}{ Trading Volume $\left(\times 10^{8}\right)$} \\
\hline & Main & SME & ChiNext & Main & SME & ChiNext & Main & SME & ChiNext & Main & SME & ChiNext \\
\hline 2004 & 1311 & 38 & & 2.74 & 1.09 & & 1.43 & 0.25 & & 4.28 & 1.56 & \\
\hline 2005 & 1305 & 50 & & 2.40 & 0.96 & & 1.66 & 0.44 & & 4.86 & 2.61 & \\
\hline 2006 & 1296 & 102 & & 6.64 & 1.98 & & 2.51 & 0.54 & & 11.97 & 2.91 & \\
\hline 2007 & 1305 & 202 & & 24.06 & 5.27 & & 3.56 & 0.63 & & 26.72 & 4.04 & \\
\hline 2008 & 1308 & 273 & & 8.74 & 2.30 & & 4.99 & 0.95 & & 17.37 & 4.36 & \\
\hline 2009 & 1315 & 327 & 36 & 17.01 & 5.16 & 4.47 & 10.38 & 1.16 & 0.18 & 35.99 & 10.04 & 1.07 \\
\hline 2010 & 1357 & 531 & 153 & 15.43 & 3.04 & 1.31 & 13.66 & 1.33 & 0.33 & 27.52 & 7.64 & 2.62 \\
\hline 2011 & 1393 & 646 & 281 & 12.36 & 2.22 & 0.89 & 15.13 & 1.74 & 0.51 & 21.00 & 5.77 & 2.71 \\
\hline 2012 & 1416 & 701 & 355 & 13.06 & 2.32 & 0.94 & 16.18 & 2.12 & 0.68 & 18.45 & 7.24 & 4.16 \\
\hline 2013 & 1412 & 701 & 355 & 12.66 & 3.64 & 2.32 & 19.39 & 2.93 & 1.21 & 25.97 & 11.76 & 8.55 \\
\hline 2014 & 1454 & 732 & 406 & 19.83 & 4.92 & 3.22 & 19.89 & 3.49 & 1.69 & 39.78 & 15.46 & 9.94 \\
\hline 2015 & 1540 & 776 & 492 & 23.05 & 8.99 & 6.52 & 20.94 & 4.51 & 2.38 & 87.79 & 32.74 & 20.20 \\
\hline 2016 & 1642 & 822 & 570 & 20.80 & 7.80 & 5.36 & 21.22 & 5.43 & 2.98 & 39.22 & 25.03 & 16.68 \\
\hline 2017 & 1854 & 903 & 710 & 21.35 & 7.88 & 4.30 & 19.95 & 6.18 & 3.08 & 33.66 & 19.28 & 12.44 \\
\hline
\end{tabular}




\section{Table A2. Individual stock regression with first half-hour returns}

The table presents the aggregated results of the firm-by-firm time-series regression with Newey-West adjusted standard errors. All denotes all the stocks, Main denotes all A-shares listed in the Shanghai Stock Exchange and in the Main board of the Shenzhen Stock Exchange, SME denotes all A-shares listed in the SME board of the Shenzhen Stock Exchange, and ChiNext all A-shares listed in the ChiNext board of the Shenzhen Stock Exchange. The dependent variable is the last half-hour return of the trading day. $r_{1 s t, t}$ denotes the first half-hour return calculated using the close price of the prior trading day and the stock price at 10:00 of the current trading day, $r_{14: 30, t}$ denotes the penultimate half-hour return calculated using the stock prices at 14:00 and 14:30 of the current trading day. Mean (Median) denotes the average (median) value of the coefficients (scaled by 100) aggregated from individual stock regressions. $t$-stat. reports the mean value of the Newey West adjusted $t$-statistics from individual stock regression. $>0$ denotes the percentage of positive coefficients. $>0 *,>0 * *$, and $>0 * * *$ denote the percentage of positive coefficients that are significant at the $10 \%, 5 \%$, and $1 \%$ level, respectively. $R^{2}$ denotes the adjusted R-squared, and Firms denotes the number of firms in the regression.

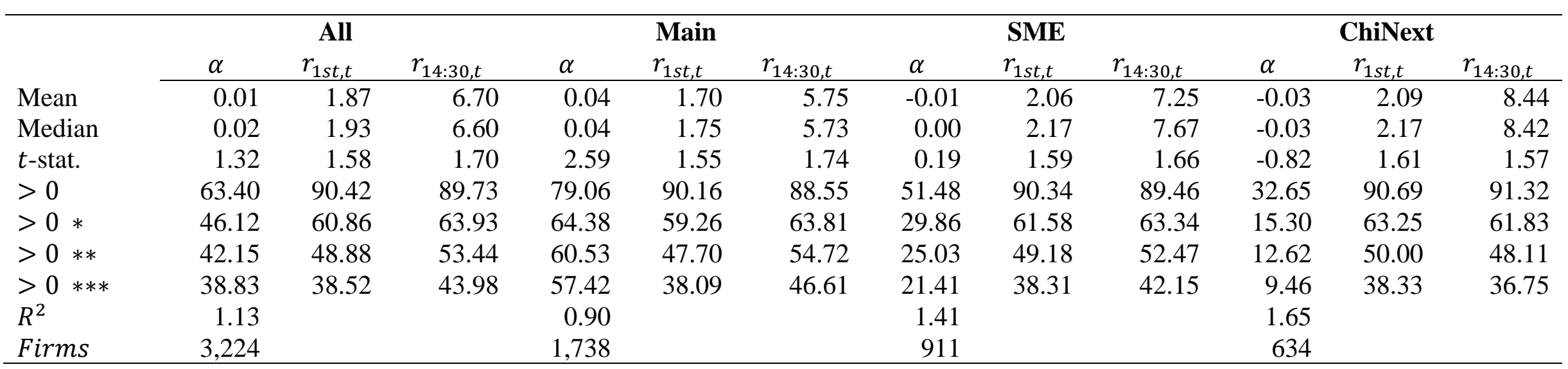




\section{Table A3. Individual stock regression with overnight returns}

The table presents the aggregated results of the firm-by-firm time-series regression with Newey-West adjusted standard errors. All denotes all the stocks, Main denotes all A-shares listed in the Shanghai Stock Exchange and in the Main board of the Shenzhen Stock Exchange, SME denotes all A-shares listed in the SME board of the Shenzhen Stock Exchange, and ChiNext all A-shares listed in the ChiNext board of the Shenzhen Stock Exchange. The dependent variable is the last half-hour return of the trading day. $r_{o v, t}$ denotes the overnight return calculated using the close price of the prior trading day and the opening price at 9:30 of the current trading day, $r_{14: 30, t}$ denotes the penultimate half-hour return calculated using the stock prices at 14:00 and 14:30 of the current trading day. Mean (Median) denotes the average (median) value of the coefficients (scaled by 100) aggregated from individual stock regressions. $t$-stat. reports the mean value of the Newey West adjusted $t$-statistics from individual stock regression. $>0$ denotes the percentage of positive coefficients. $>0 *,>0 * *$, and $>0 * * *$ denote the percentage of positive coefficients that are significant at the $10 \%, 5 \%$, and $1 \%$ level, respectively. $R^{2}$ denotes the adjusted R-squared, and Firms denotes the number of firms in the regression.

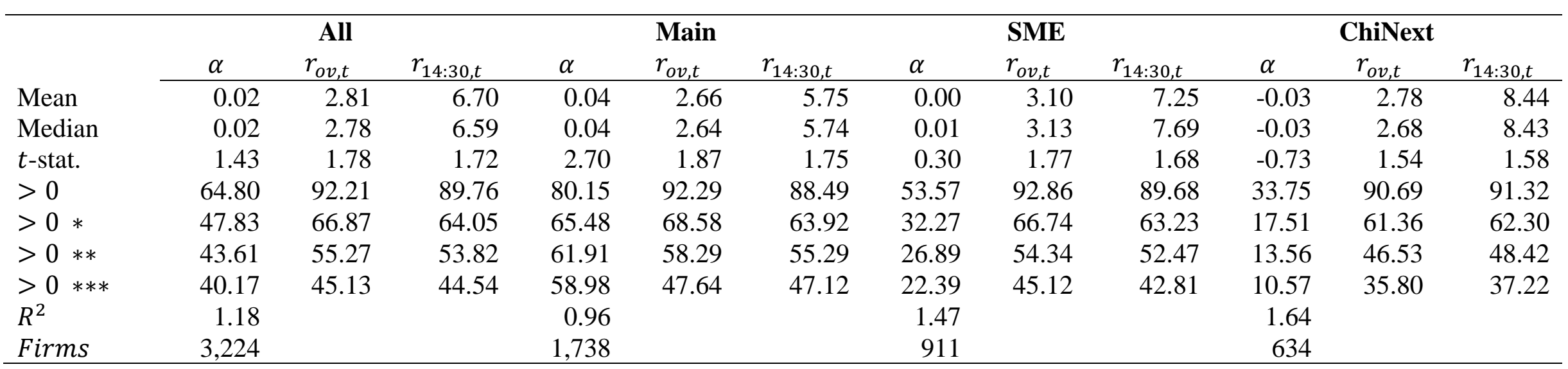




\section{Table A4. Logit Regression Model}

The table reports the logit regression model. The dependent variable is the binary variable that equals one if the trader is early-informed (late-informed) and zero otherwise. Experience denotes whether the investor has trading experience of 10 years or longer, Degree denotes whether the investor a bachelor degree or higher, Risk Tolerance denotes whether the investor is with high risk tolerance or not, and Male denotes whether the investor is male or not. The standard error of each coefficient is reported in parenthesis. Obs. denotes the number of observations. Significance at the $1 \%, 5 \%$, and $10 \%$ level is denoted as ***, **, and *, respectively.

\begin{tabular}{lrr}
\hline & $P($ early - informed $=1)$ & $P($ late - informed $=1)$ \\
\hline \multirow{2}{*}{ Experience } & $0.222^{* * *}$ & $-0.117^{* * *}$ \\
& $(0.0237)$ & $(0.0166)$ \\
Degree & $0.335^{* * *}$ & $-0.107^{* * *}$ \\
& $(0.0313)$ & $(0.0218)$ \\
Risk Tolerence & $0.335^{* * *}$ & $-0.196^{* * *}$ \\
& $(0.0265)$ & $(0.0210)$ \\
Male & $0.399^{* * *}$ & $-0.217^{* * *}$ \\
& $(0.0255)$ & $(0.0178)$ \\
$\alpha$ & $-3.074^{* * *}$ & $-1.536^{* * *}$ \\
Obs. & $(0.0224)$ & $(0.0134)$ \\
& 120,608 & 120,608 \\
\hline
\end{tabular}




\section{Reference}

Andersen, T.G., Bollerslev, T., Frederiksen, P., Ørregaard Nielsen, M., 2010. Continuous-time models, realized volatilities, and testable distributional implications for daily stock returns. Journal of Applied Econometrics 25, 233-261

Andersen, T.G., Dobrev, D., Schaumburg, E., 2012. Jump-robust volatility estimation using nearest neighbor truncation. Journal of Econometrics 169, 75-93

Asness, C.S., Moskowitz, T.J., Pedersen, L.H., 2013. Value and momentum everywhere. The Journal of Finance 68, 929-985

Avramov, D., Hore, S., 2017. Cross-sectional factor dynamics and momentum returns. Journal of Financial Markets 32, 69-96

Bajgrowicz, P., Scaillet, O., Treccani, A., 2015. Jumps in High-Frequency Data: Spurious Detections, Dynamics, and News. Management Science 62, 2198-2217

Ball, C.A., Torous, W.N., 1985. On jumps in common stock prices and their impact on call option pricing. The Journal of Finance 40, 155-173

Barndorff-Nielsen, O.E., Shephard, N., 2004. Power and Bipower Variation with Stochastic Volatility and Jumps. Journal of Financial Econometrics 2, 1-37

Barndorff-Nielsen, O.E., Shephard, N., 2006. Econometrics of Testing for Jumps in Financial Economics Using Bipower Variation. Journal of Financial Econometrics 4, 1-30

Barroso, P., Santa-Clara, P., 2015. Momentum has its moments. Journal of Financial Economics 116, 111-120

Beine, M., Lahaye, J., Laurent, S., Neely, C.J., Palm, F.C., 2007. Central bank intervention and exchange rate volatility, its continuous and jump components. International Journal of Finance \& Economics 12, 201

Bogousslavsky, V., 2016. Infrequent rebalancing, return autocorrelation, and seasonality. The Journal of Finance 71, 2967-3006

Brennan, M.J., Huh, S.-W., Subrahmanyam, A., 2015. Asymmetric effects of informed trading on the cost of equity capital. Management Science 62, 2460-2480

Calvet, L.E., Campbell, J.Y., Sodini, P., 2009. Measuring the Financial Sophistication of Households. The American Economic Review 99, 393-398

Carhart, M.M., 1997. On Persistence in Mutual Fund Performance. The Journal of Finance 52, 57-82

Chui, A.C.W., Titman, S., Wei, K.C.J., 2010. Individualism and Momentum around the World. The Journal of Finance 65, 361-392

Cooper, M.J., Gutierrez, R.C., Hameed, A., 2004. Market States and Momentum. The Journal of Finance 59, 1345-1365

Cremers, M., Halling, M., Weinbaum, D., 2015. Aggregate jump and volatility risk in the cross - section of stock returns. The Journal of Finance 70, 577-614

Economides, N., Schwartz, R.A., 1995. Electronic call market trading. Journal of Portfolio Management 21, 10-18

Elaut, G., Frömmel, M., Lampaert, K., 2018. Intraday momentum in FX markets: Disentangling informed trading from liquidity provision. Journal of Financial Markets 37, 35-51

Evans, K.P., 2011. Intraday jumps and US macroeconomic news announcements. Journal of Banking \& Finance 35, 2511-2527

Fama, E.F., French, K.R., 2012. Size, value, and momentum in international stock returns. Journal of Financial Economics 105, 457-472

Gao, L., Han, Y., Li, S.Z., Zhou, G., 2018. Market intraday momentum. Journal of Financial Economics 129, 394-414 
Georgopoulou, A., Wang, J., 2016. The Trend Is Your Friend: Time-Series Momentum Strategies across Equity and Commodity Markets. Review of Finance 21, 1557-1592

Gerace, D., Liu, Q., Tian, G.G., Zheng, W., 2015. Call auction transparency and market liquidity: Evidence from China. International Review of Finance 15, 223-255

Guo, M., Li, Z., Tu, Z., 2012. A unique "T+1 trading rule" in China: Theory and evidence. Journal of Banking \& Finance 36, 575-583

Han, X., Li, Y., 2017. Can investor sentiment be a momentum time-series predictor? Evidence from China. Journal of Empirical Finance 42, 212-239

Heston, S.L., Korajczyk, R.A., Sadka, R., 2010. Intraday patterns in the cross - section of stock returns. The Journal of Finance 65, 1369-1407

Hong, H., Lim, T., Stein, J.C., 2000. Bad news travels slowly: Size, analyst coverage, and the profitability of momentum strategies. The Journal of Finance 55, 265-295

Huang, X., Tauchen, G., 2005. The Relative Contribution of Jumps to Total Price Variance. Journal of Financial Econometrics 3, 456-499

Jegadeesh, N., Titman, S., 1993. Returns to buying winners and selling losers: Implications for stock market efficiency. The Journal of Finance 48, 65-91

Jiang, G.J., Lo, I., Verdelhan, A., 2011. Information Shocks, Liquidity Shocks, Jumps, and Price Discovery: Evidence from the US Treasury Market. Journal of Financial and Quantitative Analysis 46, 527-551

Jiang, G.J., Oomen, R.C.A., 2008. Testing for jumps when asset prices are observed with noise-a "swap variance" approach. Journal of Econometrics 144, 352-370

Jiang, G.J., Zhu, K.X., 2017. Information Shocks and Short-Term Market Underreaction. Journal of Financial Economics 124, 43-64

Johannes, M., 2004. The statistical and economic role of jumps in continuous - time interest rate models. The Journal of Finance 59, 227-260

Madhavan, A., 1992. Trading Mechanisms in Securities Markets. The Journal of Finance 47, 607-641

Maheu, J.M., McCurdy, T.H., 2004. News Arrival, Jump Dynamics, and Volatility Components for Individual Stock Returns. The Journal of Finance 59, 755-793

Menkhoff, L., Sarno, L., Schmeling, M., Schrimpf, A., 2012. Currency momentum strategies. Journal of Financial Economics 106, 660-684

Min, B.-K., Kim, T.S., 2016. Momentum and downside risk. Journal of Banking \& Finance 72, S104-S118

Moskowitz, T.J., Ooi, Y.H., Pedersen, L.H., 2012. Time series momentum. Journal of Financial Economics 104, 228-250

Nijman, T., Swinkels, L., Verbeek, M., 2004. Do countries or industries explain momentum in Europe? Journal of Empirical Finance 11, 461-481

Novy-Marx, R., 2012. Is momentum really momentum? Journal of Financial Economics 103, 429-453

Park, T.-J., Lee, Y., 2014. Informed trading before positive vs. negative earnings surprises. Journal of Banking \& Finance 49, 228-241

Pritamani, M., Singal, V., 2001. Return predictability following large price changes and information releases. Journal of Banking \& Finance 25, 631-656

Renault, T., 2017. Intraday online investor sentiment and return patterns in the US stock market. Journal of Banking \& Finance 84, 25-40

Rouwenhorst, K.G., 1998. International momentum strategies. The Journal of Finance 53, 267284

Sagi, J.S., Seasholes, M.S., 2007. Firm-specific attributes and the cross-section of momentum. Journal of Financial Economics 84, 389-434 
Yamamoto, R., 2012. Intraday technical analysis of individual stocks on the Tokyo Stock Exchange. Journal of Banking \& Finance 36, 3033-3047

Zhang, Y., Ma, F., Zhu, B., 2019. Intraday momentum and stock return predictability: Evidence from China. Economic Modelling 76, 319-329 